\title{
A pragmatic approach to adjusting early instrumental local magnitudes for seismic hazard assessments in Australia
}

\author{
Trevor I. Allen (iD)
}

Received: 26 July 2020 / Accepted: 16 March 2021 / Published online: 1 May 2021

(C) Crown 2021

\begin{abstract}
Prior to the development of Australianspecific magnitude formulae, the 1935 magnitude correction factors by Charles Richter-originally developed for southern California-were almost exclusively used to calculate earthquake magnitudes throughout Australia prior to the 1990s. Due to the difference in ground-motion attenuation between southern California and much of the Australian continent, many earthquake magnitudes from the early instrumental era are likely to have been overestimated in the Australian earthquake catalogue. A method is developed that adjusts local magnitudes $\left(M_{\mathrm{L}}\right)$ using the difference between the original (inappropriate) magnitude formulae (or look-up tables) and the Australian-specific formulae at a distance determined by the nearest recording station likely to have recorded the earthquake. Nationally, these adjustments have reduced the number of earthquakes of $M_{\mathrm{L}} \geq$ 4.5 in the early instrumental catalogue by approximately $25 \%$ since 1900 , while the number of $M_{\mathrm{L}} \geq 5.0$ earthquakes has reduced by approximately $32 \%$ over the same time period. The reduction in the number of moderate-to-large-magnitude earthquakes over the in-
\end{abstract}

\footnotetext{
Article highlights

- Earthquake magnitudes from the early instrumental era are corrected using Australian-specific attenuation corrections - Nationally, these corrections have reduced the number of magnitude 5.0 and larger earthquakes by about $32 \%$ since 1900

- These corrections yield earthquake rates that are more consistent with present-day rates using modern observational techniques.
}

T. I. Allen $(\bowtie)$

Geoscience Australia, Canberra, ACT, Australia

e-mail: trevor.allen@ga.gov.au strumental period yields long-term earthquake rates that are more consistent with present-day rates, since the development of Australian-specific magnitude formulae (approximately 1990). The adjustment of early instrumental magnitudes to obtain consistently derived earthquake catalogue is important for seismic hazard assessments.

Keywords Earthquake catalogue · Local magnitude · Magnitude adjustment $\cdot$ Seismic hazard

\section{Introduction}

Earthquake catalogues are fundamental to probabilistic seismic hazard assessments (PSHAs) in low-seismicity regions where the seismic hazard is commonly characterised by distributed seismicity source models based upon the statistical analysis of catalogues (e.g., Bommer et al. 2015; Burkhard and Grünthal 2009; Danciu et al. 2018; Gerstenberger et al. 2020; Grünthal et al. 2018; Onur et al. 2020). These assessments can be highly dependent on relationships between small-tolarge earthquakes (e.g., Gutenberg and Richter 1944) from which earthquake rupture forecasts are generated. The completeness of earthquake catalogues, together with changes in observatory practice, delivers additional challenges in ensuring the catalogue provides a consistent representation of an earthquake's size over time (e.g., Bent and Greene 2014), making the estimation of earthquake occurrence parameters highly sensitive to 
these practices and frequently changing seismic network configurations (e.g., Habermann 1986).

Modern probabilistic seismic hazard assessments rely on earthquake catalogues consistently expressed in terms of moment magnitude, $M_{\mathrm{W}}$. However, $M_{\mathrm{W}}$ is still not routinely calculated for small local events by many regional or national networks (e.g., Allen et al. 2018b; Bindi et al. 2019; Grünthal and Wahlström 2012; Halchuk et al. 2015; Mueller 2019). The preferred magnitude type calculated for small-to-moderate local earthquakes by Australia's National Earthquake Alerts Centre is local magnitude, $M_{\mathrm{L}}$. This magnitude type is also still commonly used for small-magnitude earthquakes in regions that experience high rates of seismicity (e.g., Amato and Mele 2008; Hutton et al. 2010; Ristau et al. 2016; Uhrhammer et al. 2011). For use in seismic hazard forecasts, magnitude conversion equations are often applied to convert $M_{\mathrm{L}}$ to $M_{\mathrm{W}}$. Unless these conversions are time-dependent, they commonly assume that the estimation of $M_{\mathrm{L}}$ has been consistent for the observation period.

Several workshops and reports in the past have produced recommendations for the calculation of earthquake magnitudes in Australia (e.g., Denham 1982; McGregor and Ripper 1976). The primary advances in the development of Australian-specific magnitude formulae calibrated to the crustal attenuation rates of the Australian continent occurred from the mid-1980s through to the early 1990s (e.g., Gaull and Gregson 1991; Greenhalgh and Singh 1986; Michael-Leiba and Malafant 1992; Wilkie et al. 1994). It is well documented that prior to the development of Australian-specific magnitude formulae, the Richter $(1935,1958)$ local magnitude corrections - originally developed for southern California - were almost exclusively used to calculate earthquake magnitudes throughout Australia (Leonard 2008; McGregor and Ripper 1976). To extend Richter $(1935,1958)$ to larger distances, the corrections developed by Eiby and Muir (1961) using New Zealand data were sometimes applied (e.g., Denham et al. 1985; McGregor and Ripper 1976). There was some recognition that attenuation rates in Australia were different to California based on the larger "radius of perceptibility" observed from Australian earthquakes (e.g., Drake 1974; White 1968). By contrast, ground-motion attenuation in eastern Australia was also often considered to be similar to California (e.g., Brown et al. 2001; Gibson and Dimas 2009) and some seismic observatories continued to use local magnitude equations that are appropriate for California (e.g., Bakun and Joyner 1984) until recent times. Therefore, when constructing an earthquake catalogue for use in seismic hazard assessments in Australia, hazard modellers must first identify differences in $M_{\mathrm{L}}$ estimation methods between seismic observatories when combining different catalogues, and ideally compensate for these differences in the estimation of earthquake rates.

The local magnitude scale was originally proposed by Richter (1935) as a quantitative method for estimating the relative size of earthquakes. It can be derived following (Richter 1935, 1958):

$M_{\mathrm{L}}=\log A-\log A_{0}(\Delta)$,

where the $-\log A_{0}(\Delta)$ distance correction term is scaled such that for an earthquake of $M_{\mathrm{L}} 3.0$, the horizontal peak trace displacement amplitude $A=1 \mathrm{~mm}$ recorded at an epicentral distance $\Delta=100 \mathrm{~km}$ on a standard Wood-Anderson (W-A) torsion seismograph (Anderson and Wood 1925). The distance corrections proposed by Richter are based upon the decay of peak ground displacement observed from shallow Californian earthquakes with respect to epicentral distance. They comprise the average effects of both geometrical spreading, and absorption through anelastic and scattering processes appropriate to southern California. While there are some variations in the functions used to calculate $-\log A_{0}$, many modern $M_{\mathrm{L}}$ formulae use the following form:

$-\log A_{0}(r)=n \log (r / 100)+K(r-10)+3.0$,

where $r$ is hypocentral distance, and $n$ and $K$ are constants to be determined through regression. The parameter $n$ is analogous to the geometric spreading of body waves in a homogeneous half space (e.g., Bakun and Joyner 1984).

While Australian-specific local magnitude algorithms were first developed as early as the late $1960 \mathrm{~s}$ (e.g., White 1968), regional, state and university networks did not universally adopt these algorithms, with some authorities continuing to use Californian magnitude algorithms to the present day. Consequently, the national catalogue contains a number of contributing authorities with their own methods of magnitude estimation. Californian algorithms are now well-known to overestimate magnitudes for Australia for sites at regional distances (i.e., $r>150 \mathrm{~km}$ ). This means that station magnitudes determined at these regional 
distances are likely biased high, with this bias increasing with increasing distance. The challenge for nationalscale seismic hazard assessments in Australia (e.g., Allen et al. 2018a, 2020), and potentially elsewhere, is to first develop a catalogue of earthquakes with consistently derived local magnitudes, which could then be converted to $M_{\mathrm{W}}$ for the calculation of earthquake rates. Unfortunately, a direct conversion of early instrumental $M_{\mathrm{L}}$ estimates to $M_{\mathrm{W}}$ is not possible for the Australian earthquake catalogue because any such conversion would be dependent on an event's relative distance to the seismic recording network, which itself varies in time.

An unfortunate consequence with the passage of time is the loss of original data and metadata that once underpinned earthquake catalogues. Oftentimes, an earthquake's magnitude and location may be preserved in a catalogue, but there is little information on the provenance of these source parameters in terms of magnitude algorithms, or even the original phase, amplitude and period data. For example, in the comprehensive International Seismological Centre Bulletin (Storchak et al. 2020, 2017) for the period of 1900 to 1990, no relevant period and amplitude data exist from which to re-evaluate $M_{\mathrm{L}}$ for earthquakes occurring within the Australian continent and adjacent offshore region (more than 5,900 earthquakes in total). This makes it challenging to reassess early instrumental data with modern methods and algorithms. For the 2018 National Seismic Hazard Assessment (NSHA18) of Australia (Allen et al. 2020), a pragmatic method was developed that adjusts magnitudes using the difference between the original (inappropriate) magnitude formula and the Australianspecific corrections at a distance determined by the nearest recording station likely to have recorded the earthquake (Allen et al. 2018b). Herein, the method to adjust earthquake magnitudes is summarised and its impact on seismic rate models is described.

The intent of this manuscript is not to produce a PSHA-ready catalogue - this is described in other NSHA18 publications (e.g., Allen et al. 2018b) - but to develop an interim catalogue where early instrumental local magnitudes are adjusted such that they are more consistent with modern observational methods. The interim catalogue can then be used to develop catalogue magnitudes that are consistently expressed in terms of $M_{\mathrm{W}}$. The need to use a uniform catalogue in $M_{\mathrm{W}}$ for use seismic hazard studies is well established in literature (e.g., Grünthal and Wahlström 2003; Mueller 2019;
Weatherill et al. 2016; Youngs 2012). What is less well established is the need to adjust early instrumental magnitudes due to the use of inappropriate or inconsistent magnitude algorithms. While the discussion is focussed on the Australian situation, there are potentially other regions in the world where similar problems in earthquake catalogues may exist and these should be considered for seismic hazard studies in those regions.

\section{Demonstrating the problem}

Given the sparsity of national-scale seismic monitoring networks in stable continental regions (SCRs) like Australia-where station-to-station distances can still exceed $500 \mathrm{~km}$ - it can be difficult to identify potential within-event biases in station magnitudes with distance when only a few stations may be used. If within-event biases can be identified, this is often the first symptom that the selected $M_{\mathrm{L}}$ relationship may be inappropriate for the region in which it is being applied. Furthermore, any discrepancies may only become obvious for events that are large enough to be recorded over a wide distance range. It is often only when data are made available from dense local monitoring arrays (e.g., Peck 2016) that distance biases in magnitude relationships can be identified and studied in detail.

Using an updated set of events from southeastern Australia to that used in Allen (2012), within-event station magnitude residuals (station $M_{\mathrm{L}}-$ mean event $\left.M_{\mathrm{L}}\right)$ are explored using the Richter $(1935,1958)$ and Michael-Leiba and Malafant (1992)_developed for eastern Australia $-M_{\mathrm{L}}$ relationships. Figure 1a and b show these residuals for all earthquakes with magnitudes between $M_{\mathrm{L}} 2.0$ and 5.6 (where the events are categorised based on the mean magnitude determined by the Michael-Leiba and Malafant relationship). Based on these two subplots alone, the relative performance of the two equations looks similar for distances less than approximately $300 \mathrm{~km}$. However, if only larger earthquakes with magnitudes between $M_{\mathrm{L}} 4.0$ and 5.6 are considered (Fig. 1c and d), the southern California magnitude relationship of Richter $(1935,1958)$ performs poorly when assessed against eastern Australian data, demonstrating considerable magnitude bias with distance (relative to the relationship-specific mean magnitudes). Figure 1c shows that individual station magnitudes can be up to, or exceed, 0.6 magnitude units above the mean event magnitude at hypocentral distances from 
about $600 \mathrm{~km}$. This effect is somewhat masked when the full magnitude range is considered (Fig. 1a) because the more abundant smaller earthquakes are typically recorded by a proportionally greater number of near-field recording stations (i.e., $<300 \mathrm{~km}$ ) where the California and Australian-specific local magnitude equations indicate similar rates of attenuation (Allen 2010). For larger earthquakes, California-based magnitudes have high residuals - even for nearby stations - because the mean event magnitude is determined from stations over a wider distance range. By contrast, the use of magnitude algorithms characterised for the attenuation behaviour of the Australian continental crust (e.g., Michael-Leiba and Malafant 1992) appear to generally perform well over the full distance range considered in Fig. 1.

Historically, the Australian National Seismograph Network, operated by Geoscience Australia and its predecessors, has been very sparse relative to the size of the continent, meaning that magnitudes of larger earthquakes were, more often than not, determined from relatively far-field recording stations. This potentially leads to the overestimation of mean earthquake magnitudes due to the use of Californiabased local magnitude relationships. If manifested in earthquake catalogues, these biases can have a significant impact on the estimation of earthquake
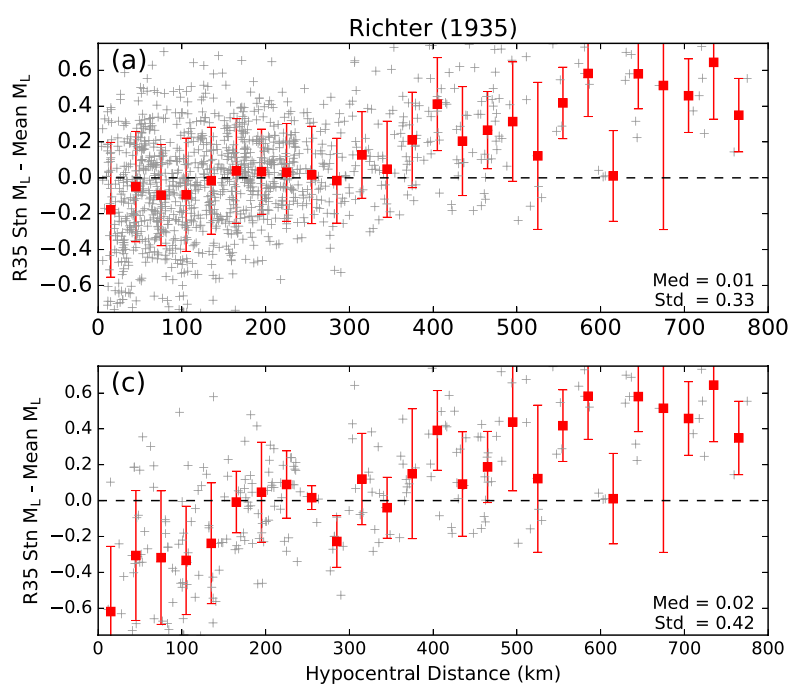

Fig. 1 Example of distance biases in some local magnitude $M_{\mathrm{L}}$ formulae that have been used by seismic networks for earthquakes in eastern Australia. Each subplot shows the within-event station magnitude residuals (station $M_{\mathrm{L}}$-mean event $M_{\mathrm{L}}$ ) for wellrecorded earthquakes in eastern Australia (grey crosses). Subplots $\mathbf{a}$ and $\mathbf{b}$ show the $M_{\mathrm{L}}$ residuals for magnitudes $2.0 \leq M_{\mathrm{L}} \leq 5.6$ for Richter (1935, 1958) and Michael-Leiba and Malafant (1992) recurrence rates for seismic hazard assessments. Consequently, we must consider methods to adjust local magnitudes to account for biases through the previous usage of inappropriate (i.e., California) magnitude relationships.

\section{Method}

Because of the likely overestimation of local magnitudes for the majority of Australian earthquakes recorded at regional distances prior to the 1990s (approximately when Australian-specific algorithms were developed), there is a need to account for magnitude biases due to the use of Californian magnitude formulae. The method first introduced by Allen (2010) and updated here corrects magnitudes using the difference between the original (inappropriate) magnitude formula (e.g., Bakun and Joyner 1984; Richter 1935) and the Australian-specific relationships (e.g., Gaull and Gregson 1991; Greenhalgh and Singh 1986; MichaelLeiba and Malafant 1992) at a distance determined by the nearest recording station likely to have recorded the earthquake. Figure 2 shows a schematic diagram of the magnitude correction procedure.
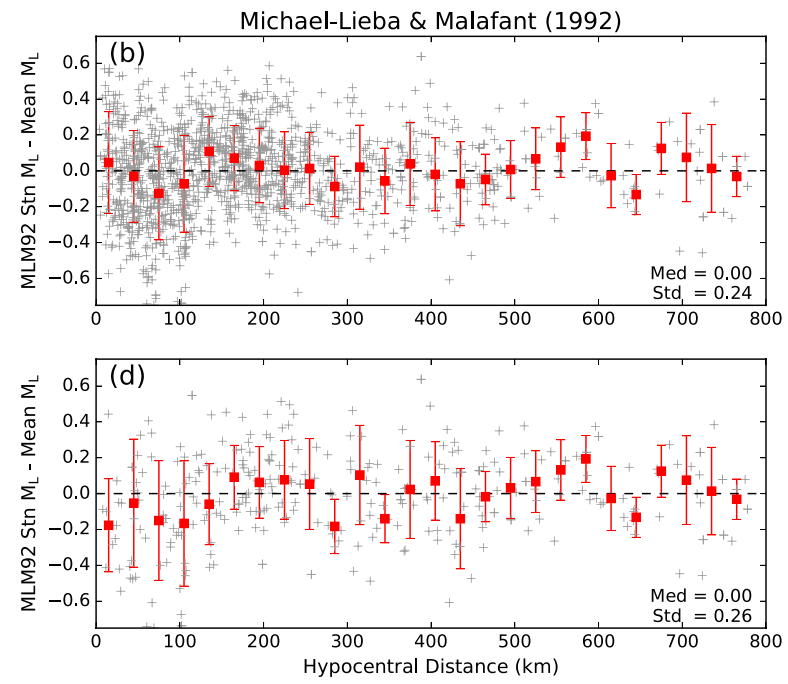

against hypocentral distance, respectively. Subplots $\mathbf{c}$ and $\mathbf{d}$ show the $M_{\mathrm{L}}$ residuals for magnitudes $4.0 \leq M_{\mathrm{L}} \leq 5.6$ for Richter (1935, 1958) and Michael-Leiba and Malafant (1992), respectively. The red squares indicate the median residuals in 20-km-wide distance bins. The error bars represent the standard deviation of the residuals 


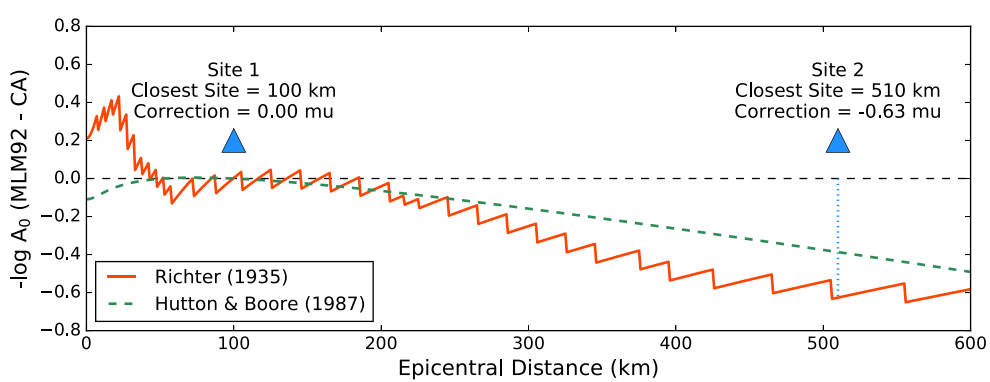

Fig. 2 Examples showing the difference between the southern California $M_{\mathrm{L}}$ of relationships of Richter $(1935,1958)$ and Hutton and Boore (1987) relative to the Australian-specific $-\log \mathrm{A}_{0} M_{\mathrm{L}}$ correction factors of Michael-Leiba and Malafant (1992; MLM92) with epicentral distance. Where the thick lines are above the dashed horizontal line, $M_{\mathrm{L}}$ is underestimated through the use of the southern Californian magnitude correction factors, while magnitudes are overestimated relative to MLM92 where the thick lines

The method considers a temporally varying seismic network configuration based on known station installation and decommission times. At distances between approximately 50 and $180 \mathrm{~km}$, it is observed that Australian local magnitude formulae are approximately consistent with Richter (1935, 1958). This is a similar observation to that found in other SCRs (e.g., Saunders et al. 2013). However, at regional distances (where many earthquakes are recorded), the so-called Richter scale overestimates $M_{\mathrm{L}}$ relative to Australian formulae (Allen 2010). Table 1 indicates the "legacy" (or "historic") local magnitude formulae that were assumed to be used to estimate early instrumental earthquake magnitudes (identified hereafter as $\left.M_{\mathrm{LH}}\right)$ in the catalogue for each geographic region defined in Fig. 3. The "target" formulae are also provided, which are the formulae used in Geoscience Australia's present-day operations (Leonard 2008), also defined by the polygons in Fig. 3.

The general procedure for adjusting the legacy local magnitudes $M_{\mathrm{LH}}$ is outlined as follows:

1. Earthquake epicentres are grouped into three zones that define the target magnitude equation to be applied as defined in Fig. 3: Western and central Australia (WCA), Southern Australia (SA) and Eastern Australia (EA);

2. For each earthquake $i$, calculate the epicentral $\Delta$ and hypocentral $r$ distances to each recording station $j$ likely to have recorded the earthquake. This uses known installation and decommission times for all seismometers of any network in Australia are below the horizontal dashed line. The imposed magnitude correction where the closest recording station is inferred to be located $100 \mathrm{~km}$ from an earthquake's epicentre (site 1) is zero. Where the closest recording station is inferred to be located greater than $500 \mathrm{~km}$ from an earthquake's epicentre (site 2), the correction would be -0.63 magnitude units [mu assuming the historical use of Richter $(1935,1958)$

(Russell Cuthbertson, pers. comm., 2017; see data and resources);

3. Identify sites used for magnitude recalculation using the following hierarchical approach:

a. Select all sites between $50 \leq r \leq 180 \mathrm{~km}$;

b. If condition $a$ cannot be satisfied, select site with minimum $r$, where $180<r \leq 1,500 \mathrm{~km}$;

c. all stations with $r<50 \mathrm{~km}$ are ignored due to the known poor performance of the Richter (1935, 1958) $-\log A_{0}$ correction factors relative to commonly used local magnitude formulae at near-source distances (e.g., Hutton and Boore 1987). The relative difference in $-\log A_{0}$ correction factors between Richter $(1935,1958)$ and Hutton and Boore (1987), which are both developed for southern California, are demonstrated in Fig. 2.

4. Given the legacy local magnitude $M_{\mathrm{LH}}$ value, backcalculate the expected earthquake peak displacement amplitude at site $j, \log A_{i j}$ assuming the correction factors, $-\log A_{0, \text { legacy, }}$, from the assumed magnitude algorithm as determined from Table 1, i.e.:

$\log A_{i j}=M_{\mathrm{LH}}+\log A_{0, \text { legacy }}(D)$

where $D$ may be either epicentral distance $\Delta$ or hypocentral distance $r$ depending on the legacy algorithm;

5. Substitute $\log A_{i j}$ values from Eq. 3 into the target formulae to obtain revised magnitude estimates, $M_{\mathrm{LR}}$ : 


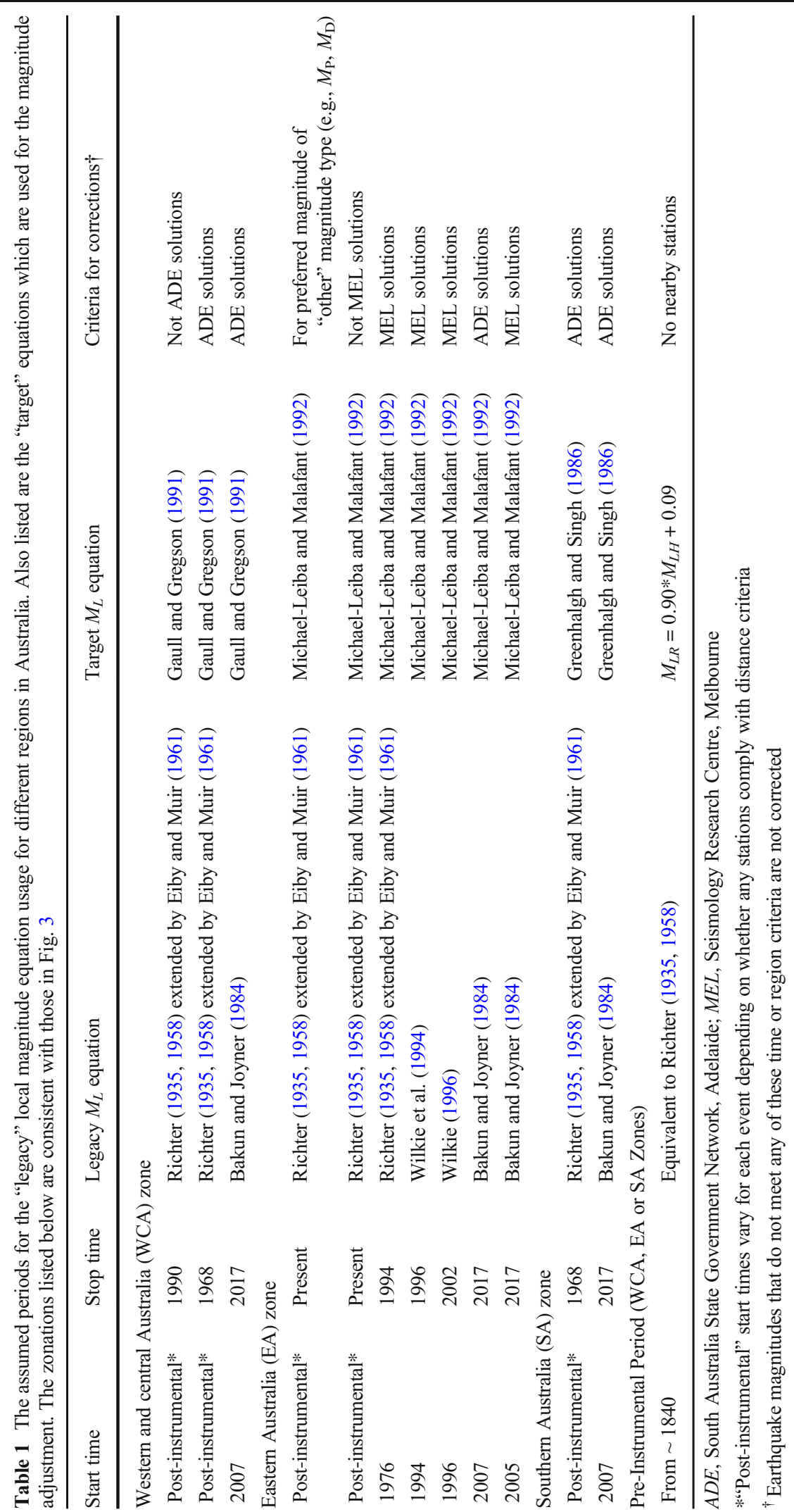


Fig. 3 Geographic regions for the three local magnitude formulae used in Geoscience Australia's present-day National Earthquake Alerts Centre: WCA, western and central Australia; EA, eastern Australia; SA, southern Australia. Epicentres of fictitious earthquakes (E1-E8) to be used in subsequent sensitivity testing and uncertainty assessment are also shown

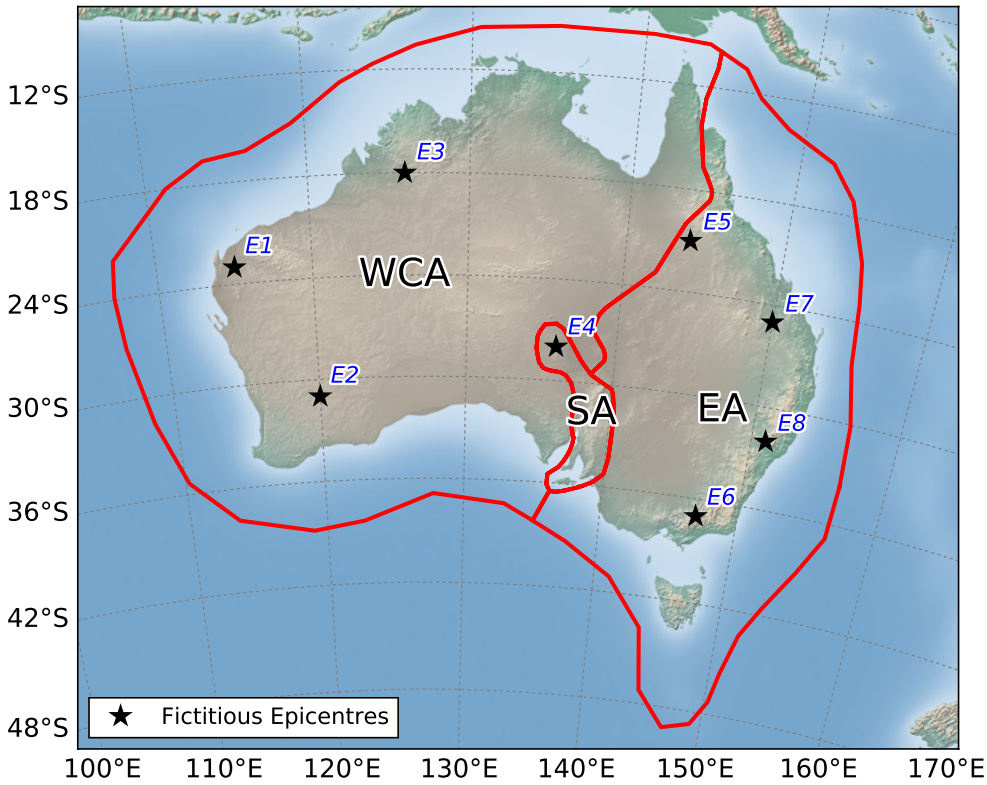

$M_{\mathrm{LR}}=\log A_{i j}-\log A_{0, \text { target }}(r)$

6. If more than one station is selected for event $i$ in step $3 a$, calculate mean revised magnitude from Eqs. 3 and 4 assuming approximately consistent attenuation behaviour between the legacy and target $M_{\mathrm{L}}$ formulae at distances $50 \leq r \leq 180 \mathrm{~km}$.

For step 3 above, additional criteria are used to account for the likelihood of early instrumental nearsource seismic records being saturated by strong ground shaking. Before the introduction of high-dynamic range digital seismic recorders, recordings of large earthquakes at near-source distances would commonly saturate, making the records unusable for magnitude estimation. Anecdotal evidence from the $1989 M_{\mathrm{L}} 5.6$ Newcastle (McCue et al. 1990) earthquake indicate that the nearest seismograph to remain on scale was over $700 \mathrm{~km}$ from the epicentre. As such, for earthquakes occurring prior to 1990 , the following additional judgement-based magnitude-distance criteria are used to account for the likelihood of peak ground velocities (PGVs) saturating during strong, near-source ground shaking:

7.1 If $4.0 \leq M_{\mathrm{LH}}<4.5$, ignore all sites $r \leq 75 \mathrm{~km}$

7.2 If $4.5 \leq M_{\mathrm{LH}}<5.0$, ignore all sites $r \leq 150 \mathrm{~km}$
7.3 If $M_{\mathrm{LH}} \geq 5.0$, ignore all sites $r \leq 250 \mathrm{~km}$

These criteria for instrumental saturation levels were evaluated relative to expected PGVs, simulated using SMSIM (Boore 2002) and applying Australian-specific attenuation parameters (Allen et al. 2007). These modelled PGVs were assessed relative to known saturation levels of early analogue seismographs (e.g., Peterson and Hutt 1981) and the saturation of early digital seismic instrumentation used by Geoscience Australia (and its predecessors). These assessments, combined with the author's observations from early digital recordings, are in reasonable agreement with the instrumental saturation criteria outlined above.

If no seismographs are identified in the aforementioned procedure (steps 1-7) within pre-defined time periods in Table 1, it is assumed that no stations were available from which to adequately record earthquakes and calculate instrumental local magnitudes. The local magnitudes assigned to these earthquakes are subsequently rescaled according to a linear relationship between original $M_{\mathrm{LH}}$ and revised $M_{\mathrm{LR}}$ magnitudes developed from earthquakes that do meet the criteria for correction (see last entry in Table 1). Earthquakes that have alternative magnitude types (e.g., magnitude of perceptibility $M_{\mathrm{P}}$ ) are considered to be equivalent to $M_{\mathrm{L}}$ (McCue 1980) and are modified according to this linear relationship.

It is worth noting that the $M_{\mathrm{L}}$ adjustment approach is likely to represent a conservative re-evaluation of early 
instrumental earthquake magnitudes because the nearest recording station should have the smallest (negative) correction - that is, the divergence of the legacy and target magnitude corrections are the smallest. If the divergence from all sites within the considered distance range $(1,500 \mathrm{~km})$ was used in this calculation, it is plausible for the magnitude adjustment to be significantly larger than the ultimate adjustment applied. Given the already significant adjustments applied to many earthquake magnitudes through the use of the nearest station, a pragmatic decision was made to use the most conservative adjustment for use in the NSHA18 catalogue (Allen et al. 2018b), such that any adjustments would have the smallest effect on seismic hazard estimates.

\section{Effects on catalogue magnitudes}

The impact of the local magnitude adjustments is both spatially and temporally dependent. Two new magnitude terms are introduced to assess the effect of these adjustments on the overall earthquake catalogue, where preferred magnitudes may be some magnitude type other than $M_{\mathrm{L}}$. These alternate magnitudes types are:

- $M_{\mathrm{X}}$ : The original unmodified catalogue magnitudes using the hierarchical logic to prioritise magnitude types as outlined in Allen et al. (2018b). $M_{\mathrm{X}}$ can be described as a mélange of magnitude types, such as $M_{\mathrm{W}}, M_{\mathrm{S}}, m_{\mathrm{b}}$ and $M_{\mathrm{L}}\left(M_{\mathrm{LH}}\right)$;

- $M_{\mathrm{XR}}$ (revised $M_{\mathrm{LR}}$ ): Original catalogue magnitudes, but replacing $M_{\mathrm{LH}}$ with $M_{\mathrm{LR}}$ for those magnitudes that are assumed to have been determined with inappropriate local magnitude formulae.

Note that any further conversion to a catalogue uniformly expressed as $M_{\mathrm{W}}$ for further use in PSHAs is not considered here.

Given these two independent catalogues, Fig. 4 shows the cumulative number of earthquakes equal to and exceeding magnitude 4.5 and 5.0 for earthquakes in the combined EA and SA magnitude zones since 1900 using the NSHA18 declustered catalogue (Allen et al. 2018b). The WCA zone is excluded from this analysis given the catalogue in this zone is less complete over the period of interest. Based on these data, the adjustment of local magnitudes represents an approximate $31 \%$ decrease in the number of earthquakes for $M \geq 4.5$ (Fig. 4a) and an approximate $44 \%$ decrease of $M \geq 5.0$ earthquakes (Fig. 4b) in eastern and southern Australia since 1900. Nationally, the use of this magnitude adjustment method has led to a reduction of $25 \%$ of $M_{\mathrm{L}} \geq$ 4.5 earthquakes since 1900 , with a reduction of approximately $32 \%$ of $M_{\mathrm{L}} \geq 5.0$ earthquakes over the same period. Also depicted in Fig. 4 are linear cumulative seismicity curves that are fitted to the corresponding catalogue curves for the post-1990 period only. These represent activity rates inferred from magnitude estimates made from digital records using Australianspecific $M_{\mathrm{L}}$ formulae, which should be unbiased. Assuming there has been no significant increase in seismicity since the beginning of the twentieth century, these lines should back-project to the origin. While not intersecting exactly at zero, the projections for the adjusted magnitude catalogue $\left(M_{\mathrm{XR}}\right)$ most closely intersect near the origin. In contrast for the $M_{\mathrm{X}}$ original catalogue, the intercepts are significantly larger than zero, which would suggest that rates of moderate-to-large earthquakes reported in catalogues have decreased over time, particularly since the development and adoption of Australian-specific $M_{\mathrm{L}}$ formulae. From Fig. 4, one might also observe a significant drop in earthquake rates from the mid-1930s to the mid-1950s, until the rates increase again. This likely demonstrates a gap in catalogue completeness in eastern Australia around this period of time. One may hypothesise and suggest, had it not been for this gap in catalogue completeness, even the back-projection of the revised $M_{\mathrm{XR}}$ curves would further overestimate the number of $M_{\mathrm{XR}} \geq 4.5$ and $M_{\mathrm{XR}}$ $\geq 5.0$ events, further suggesting that the magnitude adjustments proposed herein may be conservative. The cumulative trends in earthquake rates shown in Fig. 4 for the post-1990 period are not dissimilar to trends of reduced rates of earthquakes demonstrated for modern instrumental catalogues elsewhere in the world (e.g., Beauval et al. 2020; Rong et al. 2011).

Figure 5 shows the annual number of earthquakes equal to or exceeding $M_{\mathrm{X}} 4.5$ for a declustered earthquake catalogue nationally since 1960 (Allen et al. 2018b). The average annual number of earthquakes equal to or exceeding $M_{\mathrm{X}} 4.5$ before and after 1990 suggests that higher local magnitudes $\left(M_{\mathrm{LH}}\right)$ were more commonly assigned to moderate-magnitude earthquakes prior to the development of Australian-specific local magnitude algorithms. For example, the unmodified catalogue gives an average of approximately six earthquakes per year equal to or exceeding $M_{\mathrm{X}} 4.5$ prior to 1990 . By contrast, post-1990, $M_{\mathrm{X}} \geq 4.5$ earthquakes 
(a)

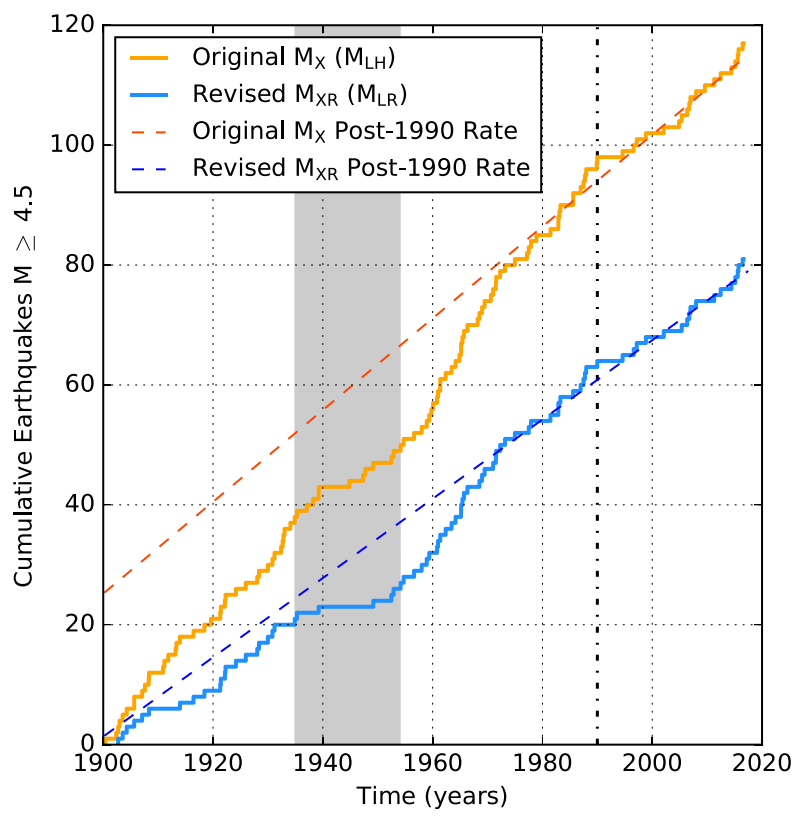

Fig. 4 Cumulative number of earthquakes equal to or exceeding magnitude a 4.5 and b 5.0 for earthquakes in the eastern Australia (EA) and southern Australia (SA) zones since 1900 using the NSHA18 declustered catalogue (Allen et al. 2018b). The different curves show the original preferred magnitudes $\left(M_{\mathrm{X}}\right)$ and preferred

occur at roughly half that rate (Fig. 5). Following the correction of local magnitudes $\left(M_{\mathrm{LR}}\right)$, the number of revised magnitudes $M_{\mathrm{XR}} \geq 4.5$ occurring annually prior to 1990 is slightly greater than four. Two possible conclusions can be drawn: (1) either this legitimately demonstrates a period of higher earthquake activity within the Australian continent over decadal time scales, or (2) the methods implemented here have adjusted potentially erroneous magnitudes, such that the pre1990 earthquake rates are more consistent with rates of moderate events after 1990. The latter option appears to be the most plausible assuming a Poisson (time independent) process on a continental scale. Note that post1990 , the average annual rates of $M_{\mathrm{X}}$ and $M_{\mathrm{XR}}$ being equal to or exceeding magnitude 4.5 are almost identical, indicating that only minor adjustments have been applied to the catalogue during this time period.

Figure 6 shows a map indicating the spatial change in local magnitude $M_{\mathrm{L}}$ using the adjustment process outlined above for earthquakes occurring prior to 1990. This map generally depicts larger magnitude adjustments for earthquakes in more remote regions of western and central Australia, a region that has (b)

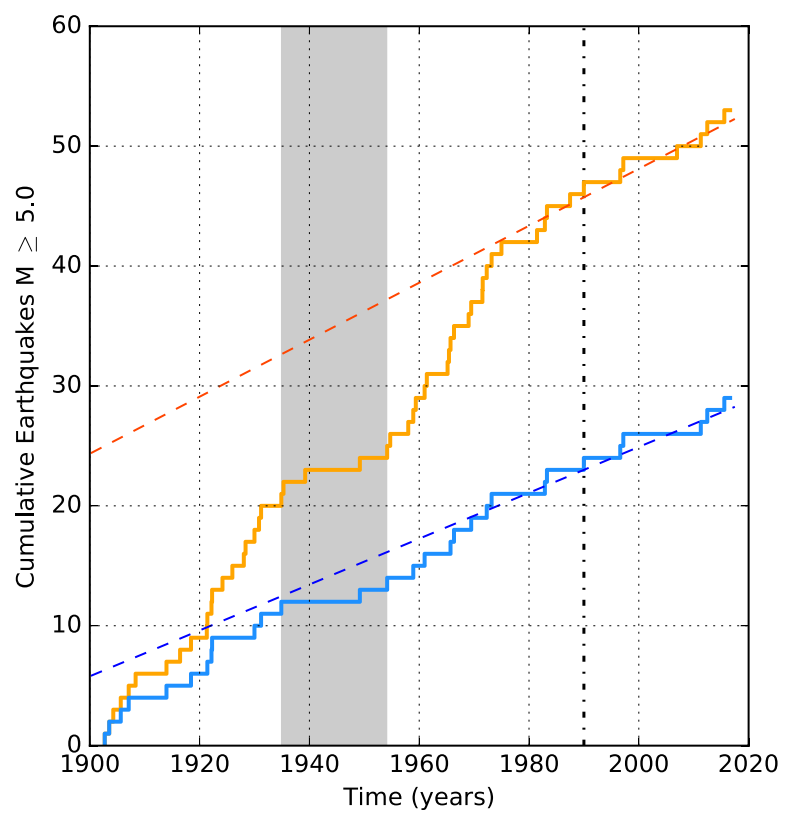

magnitudes with modified $M_{\mathrm{L}}\left(M_{\mathrm{XR}}\right)$. The post-1990 rates for both curves are back-projected to 1900 . While not intersecting at zero, the adjusted magnitude projections most closely intersect near this origin. The grey shaded zone represents a time period where the catalogue may not be complete at the specified magnitude level

historically had sparse seismic monitoring infrastructure. It is noted that the larger early instrumental earthquakes within the catalogue typically demonstrate the largest change in magnitude. There are two main reasons for this observation: (1) seismic networks in the past (particularly prior to the 1960s) had very limited capacity to detect and locate small-magnitude earthquakes in remote areas of Australia, so only the larger events are represented in early instrumental catalogues, and (2) because the network was generally quite sparse, there were often large distances between the earthquake's epicentre and the nearest recording station. This translates into a larger magnitude adjustment (see Fig. 2).

\section{Extension to pre-instrumental earthquakes}

For those earthquakes occurring prior to the development and expansion of local and regional seismic networks across Australia (from approximately the 1950s; Leonard 2008), it is assumed that very few stations were available from which to adequately record earthquakes 


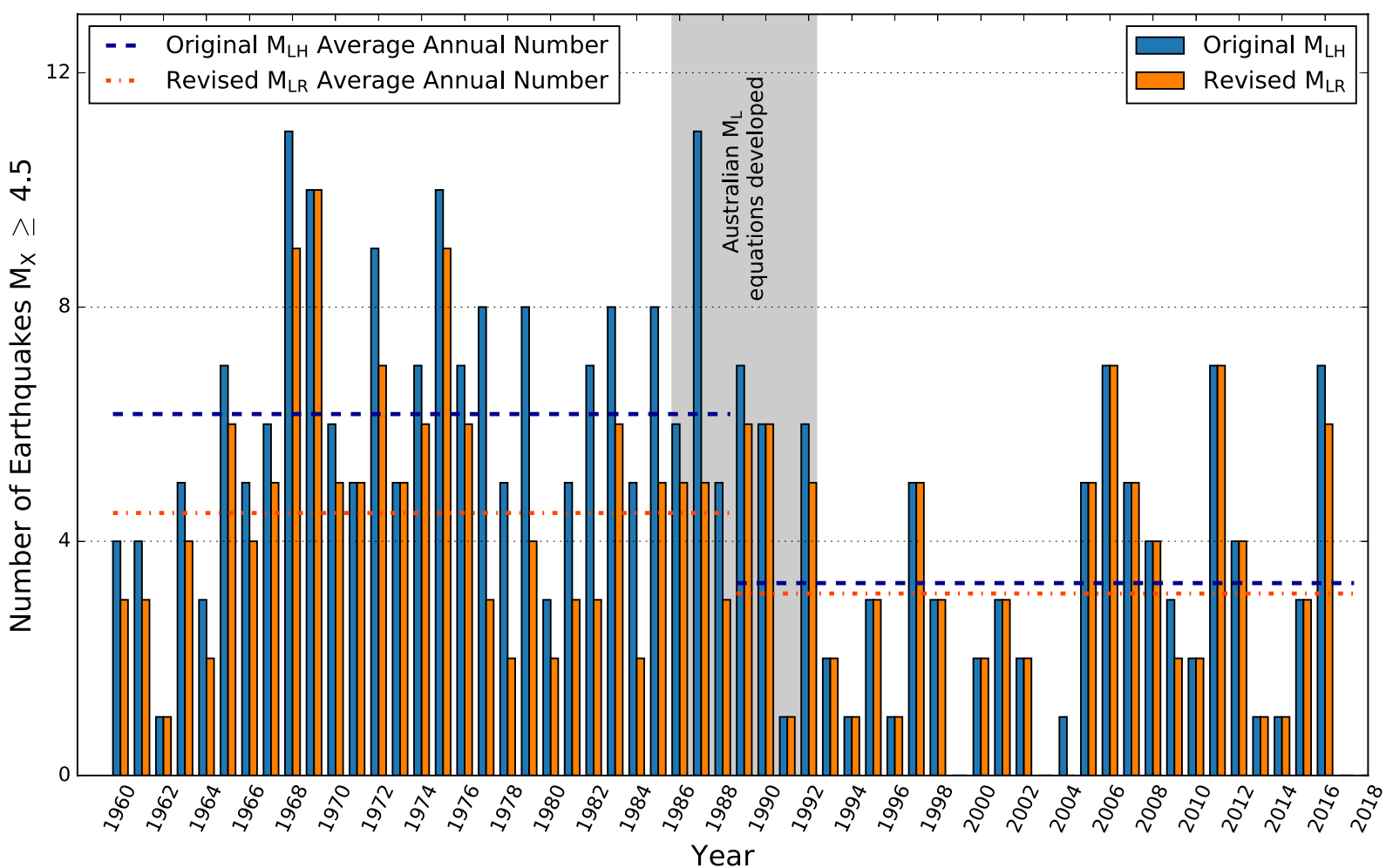

Fig. 5 Bar chart indicating the annual number of Australian earthquakes equal to or exceeding $M_{\mathrm{X}}$ or $M_{\mathrm{XR}} 4.5$ for a declustered earthquake catalogue (Allen et al. 2018b). Blue columns represent legacy magnitudes (using $M_{\mathrm{LH}}$ ) while the orange columns indicate revised local magnitudes $\left(M_{\mathrm{LR}}\right)$ based on the $M_{\mathrm{L}}$ adjustment procedure above. Dashed horizontal lines indicate the average annual number of earthquakes $M_{\mathrm{X}} \geq 4.5$ for the periods before

and calculate their magnitudes. Indeed, the magnitudes of many earthquakes prior to the 1960s are likely to be scaled by their felt radius. Many of the earthquake magnitudes calculated using felt radii have been calibrated to events with instrumental (Richter 1935) magnitudes (e.g., McCue 1980). The magnitudes of these earthquakes are subsequently adjusted according to a regression between the legacy and revised magnitudes determined from post-1950 (to approximately 1990) earthquakes (Fig. 7), where those magnitudes are considered to be equivalent to $M_{\mathrm{L}}$. Orthogonal distance regression (e.g., Castellaro et al. 2006) between the original $M_{\mathrm{LH}}$ and revised $M_{\mathrm{LR}}$ magnitudes yields the following relationship:

$M_{\mathrm{LR}}=0.90 \times M_{\mathrm{LH}}+0.09$ and after local magnitude formulae are expected to have been deployed in Australian seismological observatories in approximately 1990 (see Table 1). The shaded region between 1986 and 1992 represents the time period where the Australian-specific $M_{\mathrm{L}}$ equations currently in use at Geoscience Australia were developed and published

\section{Effect of magnitude adjustments on earthquake rates}

This manuscript does not investigate the changes in probabilistic hazard estimates due to the magnitude adjustments. However, given earthquake recurrence statistics control hazard computations, particularly in distributed source seismicity models, inferences on the likely changes to seismic hazard based on these magnitude adjustments can be explored. Gutenberg-Richter magnitude-frequency distributions (MFDs) were fitted based on the two catalogues: the $M_{\mathrm{X}}$-based catalogue using unmodified magnitudes where the preferred magnitude type may be $M_{\mathrm{W}}, M_{\mathrm{S}}, m_{\mathrm{b}}, M_{\mathrm{L}}\left(M_{\mathrm{LH}}\right)$, etc., and the $M_{\mathrm{XR}}$-based catalogue which is the same as above, but uses the revised local magnitude, $M_{\mathrm{LR}}$. It is recognised 
Fig. 6 Map of Australian epicentres for pre-1990 earthquakes $M_{\mathrm{LR}} 3.0$ and above indicating the change in local magnitude using the proposed adjustment method. Changes most commonly translate to a decrease in magnitude. Thick black polygons indicate the geographic regions for the three local magnitude formulae as used by Geoscience Australia and as defined in Fig. 3 and Table 1. Note, not all earthquakes mapped here use $M_{\mathrm{L}}$ as the preferred magnitude type

Fig. 7 Orthogonal distance regression (ODR) between original $M_{\mathrm{LH}}$ and revised $M_{\mathrm{LR}}$ magnitudes
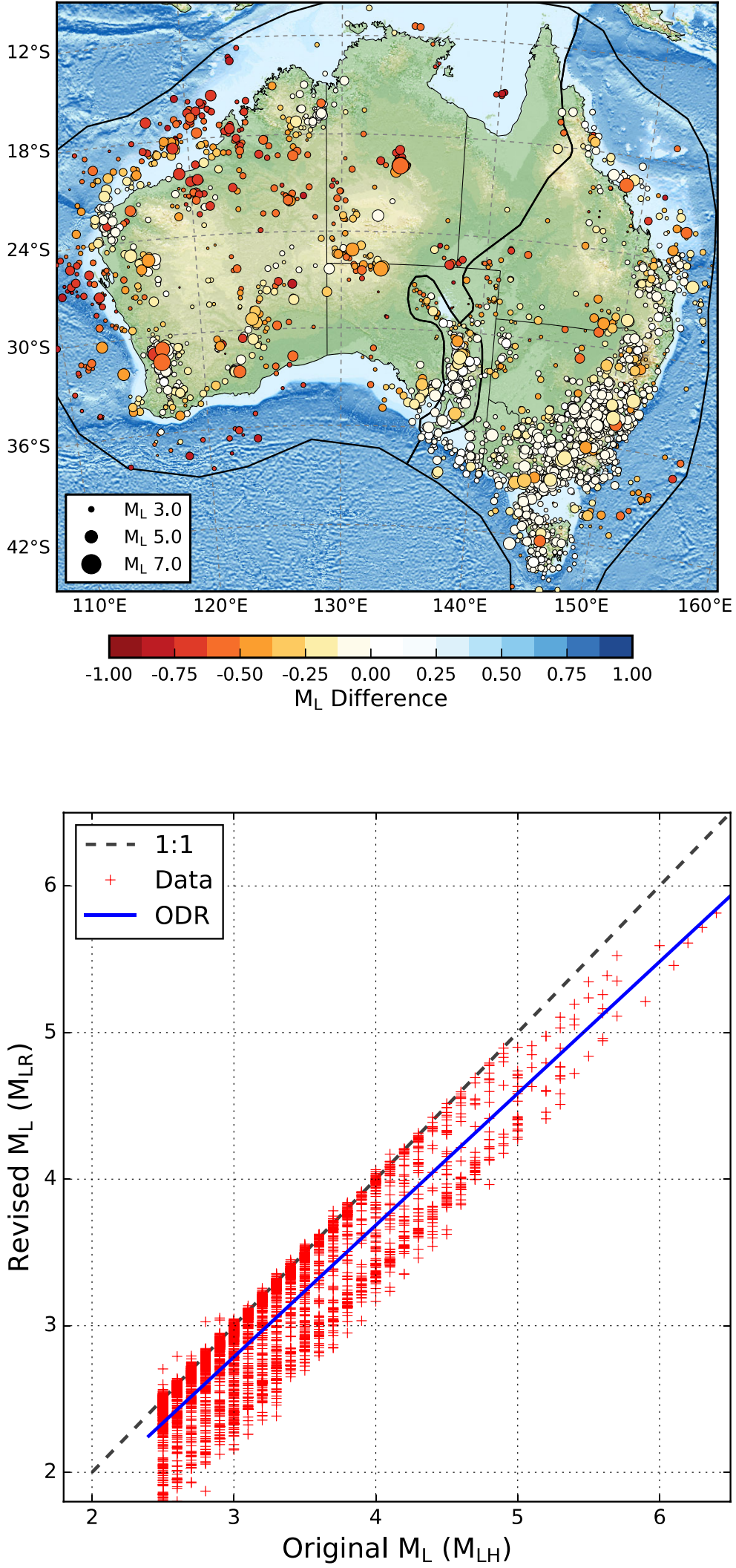
that calculating MFDs using mixed magnitude types is not best practice and the use of an $M_{\mathrm{W}}$-only catalogue should be used in PSHAs. While not explicitly mentioned in literature, the use of mixed magnitude types for defining earthquake rates has, until recently, been common practice in Australian seismic hazard studies (e.g., Burbidge 2012; Cuthbertson 2016; Gibson and Dimas 2009; Gibson and Sandiford 2013; Leonard et al. 2014a, 2014b). As such, this practice is followed herein to demonstrate the effects of the local magnitude adjustments, prior to any homogenisation to $M_{\mathrm{W}}$. Further discussion on the use of catalogues uniformly expressed in terms of $M_{\mathrm{W}}$ for hazard studies in Australia may be found in Ghasemi and Allen (2017) and Allen et al. (2018b).

The Gutenberg-Richter magnitude-frequency distributions (MFDs) can be described by the relationship:

$\log _{10} N=a-b m$

where $N$ is the annualised number of earthquakes greater than or equal to a magnitude $m$, where $m$ is either $M_{\mathrm{X}}$ or $M_{\mathrm{XR}}$. The parameter $a$ is the logarithm of the annualised number of $m \geq 0$ earthquakes, and $b$ is a parameter that determines the relative proportion of small to large earthquakes (Gutenberg and Richter 1944). The annual number of earthquakes equal to or exceeding $m=0, N_{0}$, is given as:

$\log _{10} N_{0}=a$.

An estimate of the changes to the earthquake rates are calculated for two representative area sources that are assumed to have had approximately uniform magnitude completeness over time (Fig. 8). These area sources are updated from Leonard (2008), with respective magnitude completeness models presented in Allen et al. (2018b). The MFD calculations used the Weichert (1980) maximum likelihood method. Because local magnitude is the most commonly determined magnitude type for Australian earthquakes, particularly of small-to-moderate magnitudes, these magnitude types will dominate the maximum likelihood earthquake rate calculations. Earthquakes that use $M_{\mathrm{W}}, M_{\mathrm{S}}$ or $m_{\mathrm{b}}$ as their preferred magnitude type are limited in number and are usually assigned to larger magnitude earthquakes. In the NSHA18 earthquake catalogue (Allen et al. 2018b), non- $M_{\mathrm{L}}$ magnitude types represent approximately $6 \%$ of the events for earthquakes of $M_{\mathrm{W}} \geq 3.0$ within continental Australia. As a consequence, these other magnitude types will have little impact on the calculated earthquake rates.

Figure 8 shows the difference in earthquake rates for the two area source zones based on the use of the $M_{\mathrm{X}}$ (using $M_{\mathrm{LH}}$ ) and $M_{\mathrm{XR}}$ (using $M_{\mathrm{LR}}$ ) earthquake catalogues described above. Gutenberg-Richter magnitudefrequency statistics for the representative area sources are provided in Table 2. For these two source zones, there is little change in $b$-values between each of the two catalogues. For historically well-instrumented regions such as southeastern Australia (SEA; Fig. 8a), there is little change in the overall earthquake rates from the implementation of the magnitude adjustments. However, the SEA source zone possessed a high number of moderate-to-large-magnitude events in the $M_{\mathrm{X}}$-based catalogue, with a "bulge" in the MFD centred around $M_{X}$ 5.2. While there is little change in the GutenbergRichter MFD between the two catalogues for this source zone given the maximum likelihood regression approach, there is clearly a reduction in this bulge based on the adjusted catalogue. For the cratonic Australia (CA) zone (Fig. 8b), the Gutenberg-Richter activity rate has reduced due to the sparser recording network (thus larger negative corrections to magnitudes). However, the $b$-value remains similar (Table 2). Note that many of the larger earthquakes in this CA zone were expressed in magnitude types other than $M_{\mathrm{L}}$. Consequently, there is little-to-no difference in the cumulative rates for earthquakes of $M_{\mathrm{X}} \gtrsim 5.6$.

\section{Magnitude adjustment uncertainty}

Given Australia's sparse recording networks relative to the size of the continent, magnitude uncertaintiesdefined of the standard deviation of the inter-station magnitudes - are commonly larger than 0.3 magnitude units, even in the era of modern digital networks using local magnitude formulae calibrated to Australian crustal conditions (Fig. 9). Of particular note is the median $M_{\mathrm{L}}$ uncertainty calculated for the southern Australia zone (Fig. 9d), which is approaching 0.5 magnitude units. Therefore, it might be expected that magnitude uncertainties for the early- and pre-instrumental eras are likely to be even larger (e.g., Musson 2012), perhaps even exceeding 0.5 magnitude units (e.g., McGuire 1993; Mueller 2019; Rong et al. 2011; Stucchi et al. 2013; Traversa et al. 2018). It is noted that the use of an indiscriminate magnitude adjustment process as 
(a)

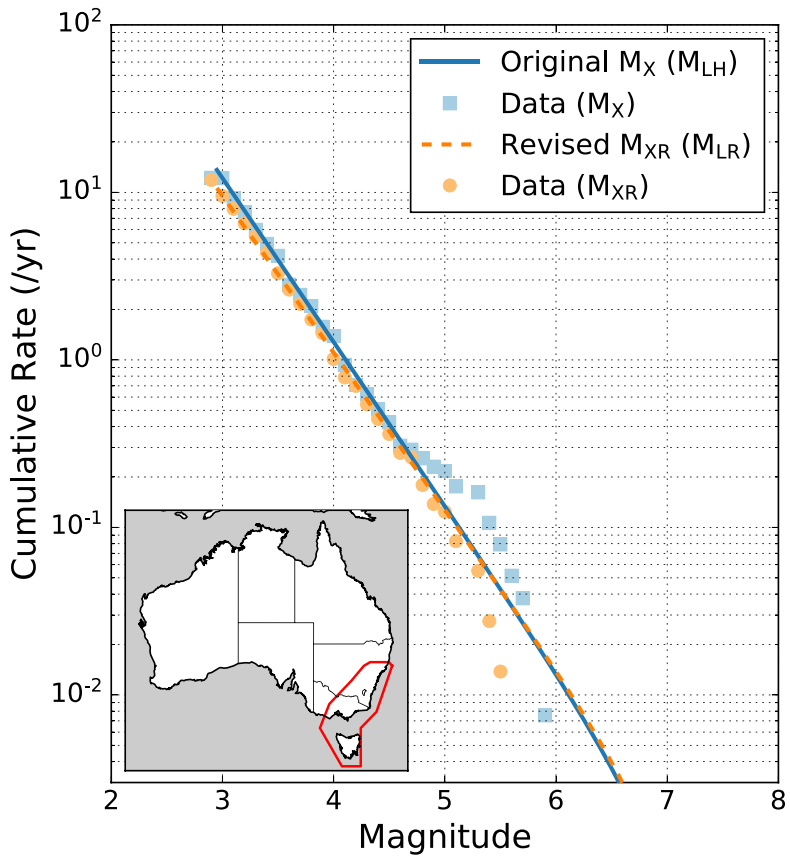

Fig. 8 The difference in earthquake rates through the use of alternative preferred magnitudes for the a southeastern Australia (SEA) area source and the $\mathbf{b}$ cratonic Australia (CA) source. The

proposed herein adds additional, but unquantified uncertainty to catalogue magnitudes, an already uncertain parameter for many early instrumental events.

Because it is not often possible to access original amplitude and period data recorded at each seismic station to re-evaluate $M_{\mathrm{L}}$ using modern techniques, the abovementioned magnitude adjustment technique must make assumptions about both the magnitude algorithm used to determine the original magnitude and the configuration of the seismic network over time. Furthermore, the technique uses only the nearest station likely (b)

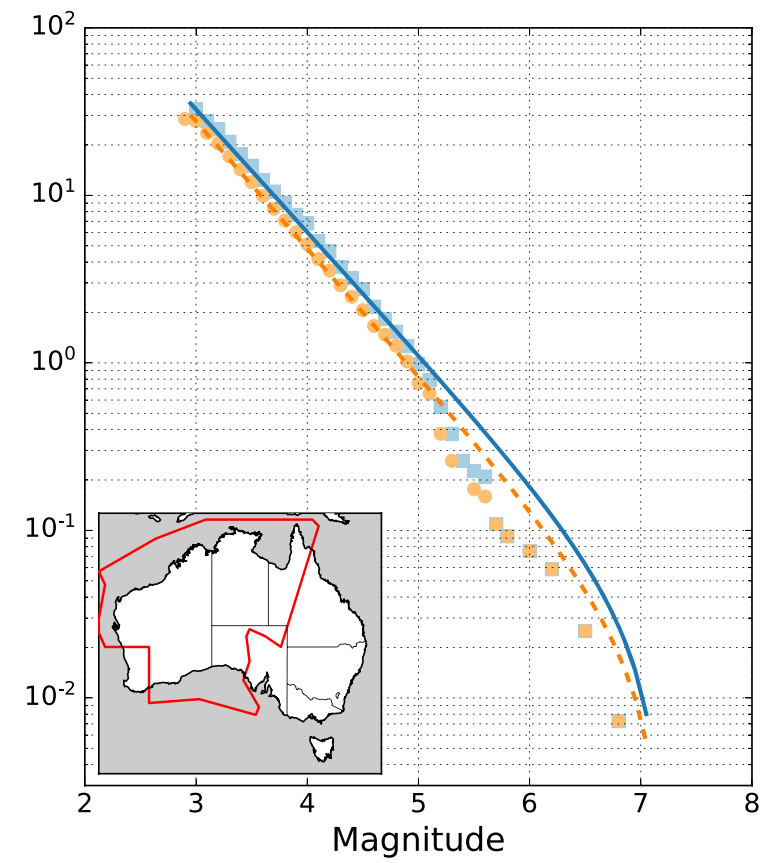

figure shows Gutenberg-Richter MFDs fitted assuming an $M_{\mathrm{X}}$ or $M_{\mathrm{XR}}$ declustered catalogue. Note that the magnitude-recurrence data from $M_{\mathrm{X}}$ or $M_{\mathrm{XR}}$ may superimpose each other in these figures

to have recorded the earthquake to determine the magnitude correction. This assumption will be at a distance where the differences between the legacy $\left(-\log A_{0, \text { legacy }}\right)$ and target attenuation corrections $\left(-\log A_{0, \text { target }}\right)$ are smallest (see Fig. 2).

One key assumption in the procedure described above is that all seismic stations were operational $100 \%$ of the time from their installation until their decommissioning. Furthermore, the stations used for the corrections span multiple seismic networks, and while there has been some sharing of phase picks and

Table 2 Gutenberg-Richter magnitude-frequency parameters for alternative NSHA18-Cat preferred magnitude types for the southeastern Australia (SEA) and cratonic Australia (CA) area sources described in Allen et al. (2018b)

\begin{tabular}{|c|c|c|c|c|c|c|}
\hline Source zone & Source area $\left(\mathrm{km}^{2}\right)$ & Magnitude adjustment type & \# Earthquakes passing completeness & $N_{0}$ & $\begin{array}{l}b \text { - } \\
\text { value }\end{array}$ & $b$-value uncertainty \\
\hline \multirow[t]{2}{*}{ SEA } & 741,284 & $M_{\mathrm{X}}\left(M_{\mathrm{LH}}\right)$ & 667 & 10467 & 0.98 & 0.035 \\
\hline & & $M_{\mathrm{XR}}\left(M_{\mathrm{LR}}\right)$ & 641 & 6093 & 0.94 & 0.037 \\
\hline \multirow[t]{2}{*}{$\mathrm{CA}$} & $7,496,441$ & $M_{\mathrm{X}}\left(M_{\mathrm{LH}}\right)$ & 1326 & 5043 & 0.73 & 0.018 \\
\hline & & $M_{\mathrm{XR}}\left(M_{\mathrm{LR}}\right)$ & 1153 & 5228 & 0.76 & 0.020 \\
\hline
\end{tabular}

$M_{\mathrm{X}}\left(M_{\mathrm{LH}}\right)$, original (legacy) preferred magnitude; $M_{\mathrm{XR}}\left(M_{\mathrm{LR}}\right)$, original magnitude using revised $M_{\mathrm{L}}\left(M_{\mathrm{LR}}\right)$. The $b$-value uncertainty is equivalent to 1 standard deviation relative to the mean $b$-value 

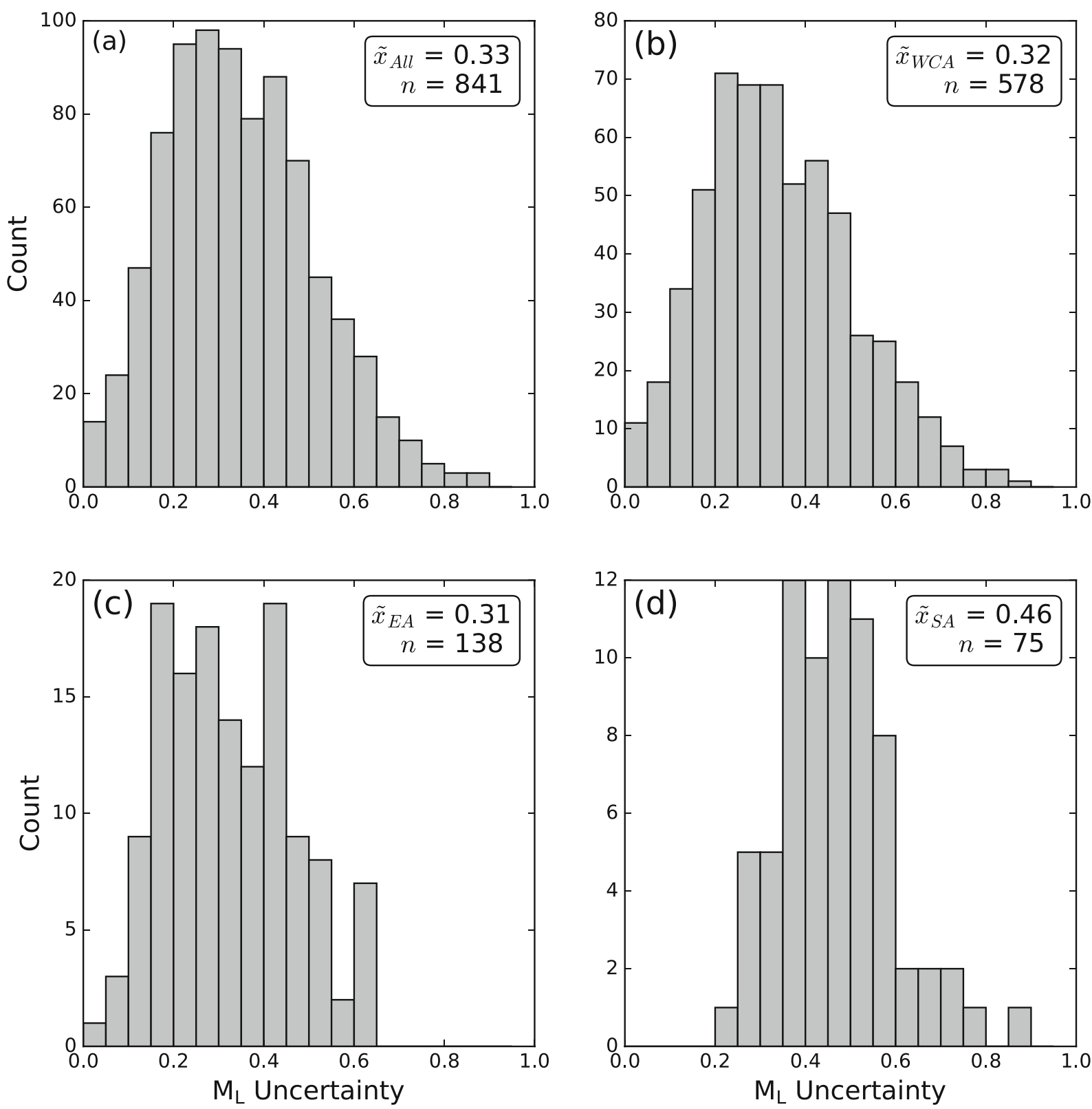

Fig. 9 Histograms of local magnitude uncertainty calculated by Geoscience Australia's National Earthquake Alerts Centre from May 2018 through December 2020 for earthquakes in a all $M_{\mathrm{L}}$ regions, b western and central Australia (WCA), c eastern Australia (EA) and $\mathbf{d}$ southern Australia (SA) for earthquakes of $M_{\mathrm{L}} 2.5$

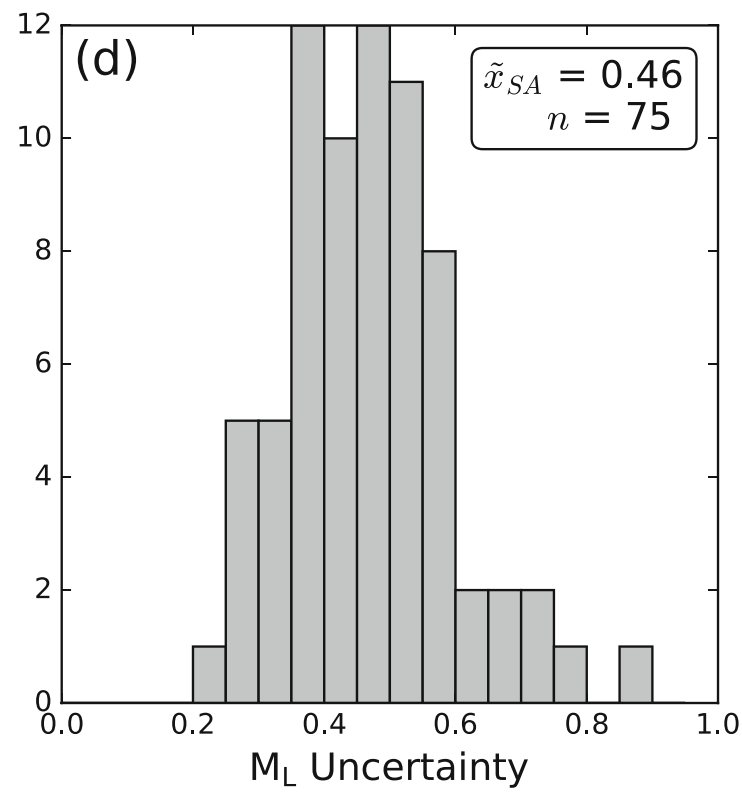

and larger. The regions are defined in Fig. 3 and the number of events (n) and median $(\widetilde{x}) M_{\mathrm{L}}$ uncertainty for each region is shown within each subplot

amplitude data between seismic observatories, this practice was likely not consistent for every event across the early instrumental era. Therefore, the magnitude adjustments applied using the methods proposed herein, which in many cases is based on the nearest seismometer, may express some biases due to the assumption that all stations were operable all of the time and that their

data were available to all seismic observatories in the determination of the preferred earthquake magnitude. The magnitude adjustment method was also largely chosen because it would lead to the most conservative (i.e., smallest) correction.

Using a suite of fictitious earthquake epicentres distributed across the Australian continent (shown in Fig. 
3) and the known station installation and decommission times, the variability and range of the magnitude adjustments that could be applied over time is explored assuming that seismic networks were not always $100 \%$ operable. For each fictitious epicentre, E1-E8, the "theoretical" number of seismic stations installed within $1,500 \mathrm{~km}$ of the epicentre, were identified for each year between 1950 and 1990. To simulate the case where one or more seismometers are not operable, the theoretical number of seismometers that would have recorded the event was reduced by between 65 and 95\% (chosen
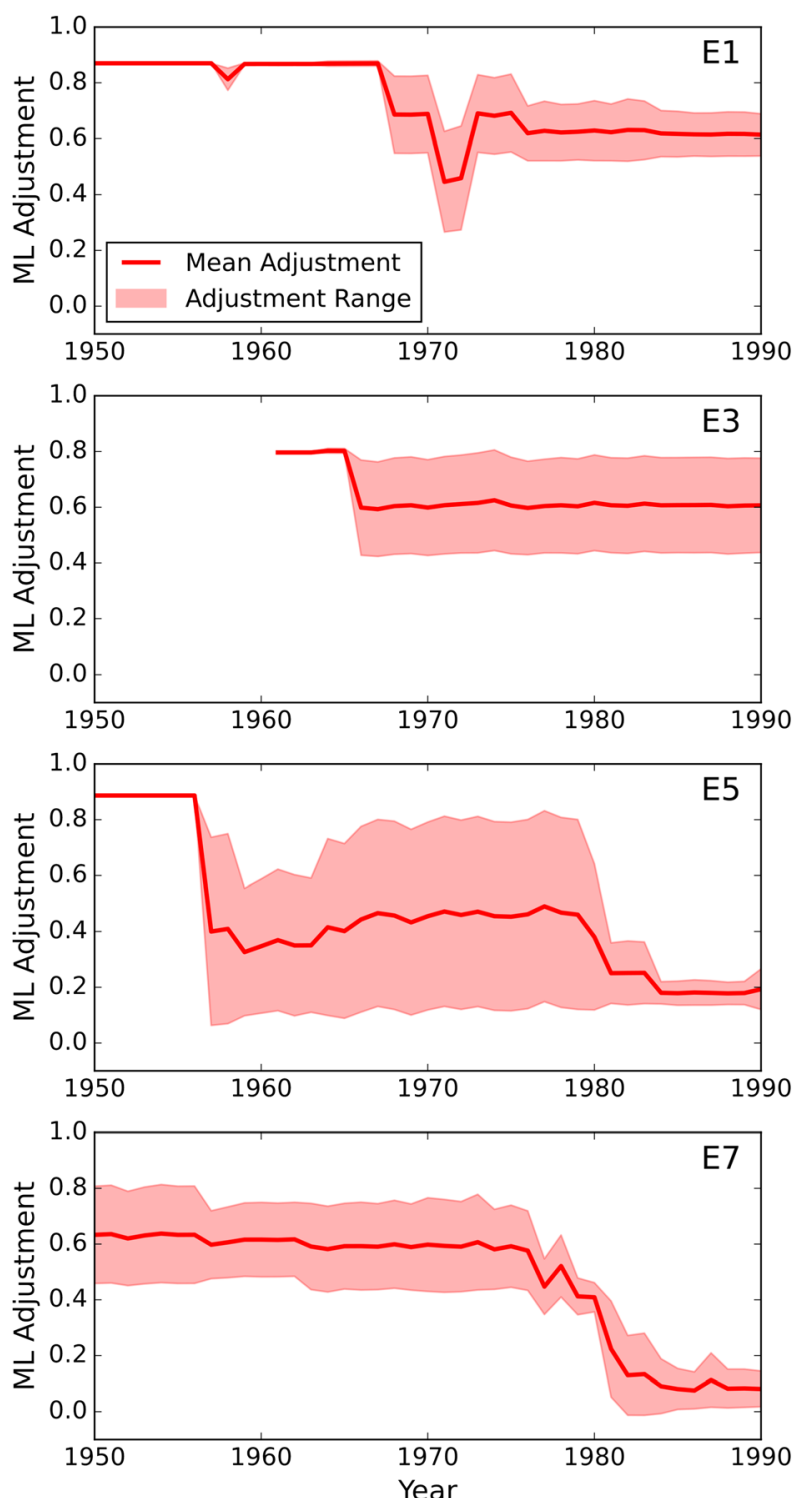

randomly). This also implicitly accounts for situations where the theoretical stations may span different seismic networks, and thus, the data may not be available for analysis by any particular observatory. The "actual" number of stations was then randomly drawn from the known, time-dependent station list within the $1,500 \mathrm{~km}$ range. The magnitude adjustments were subsequently calculated for a hypothetical earthquake of $M_{\mathrm{L}} 4.5$ (i.e., stations of $r \leq 75 \mathrm{~km}$ are ignored) using the procedure outlined in the Method section. For each fictitious epicentre, E1-E8 and each year from 1950 to 1990 ,
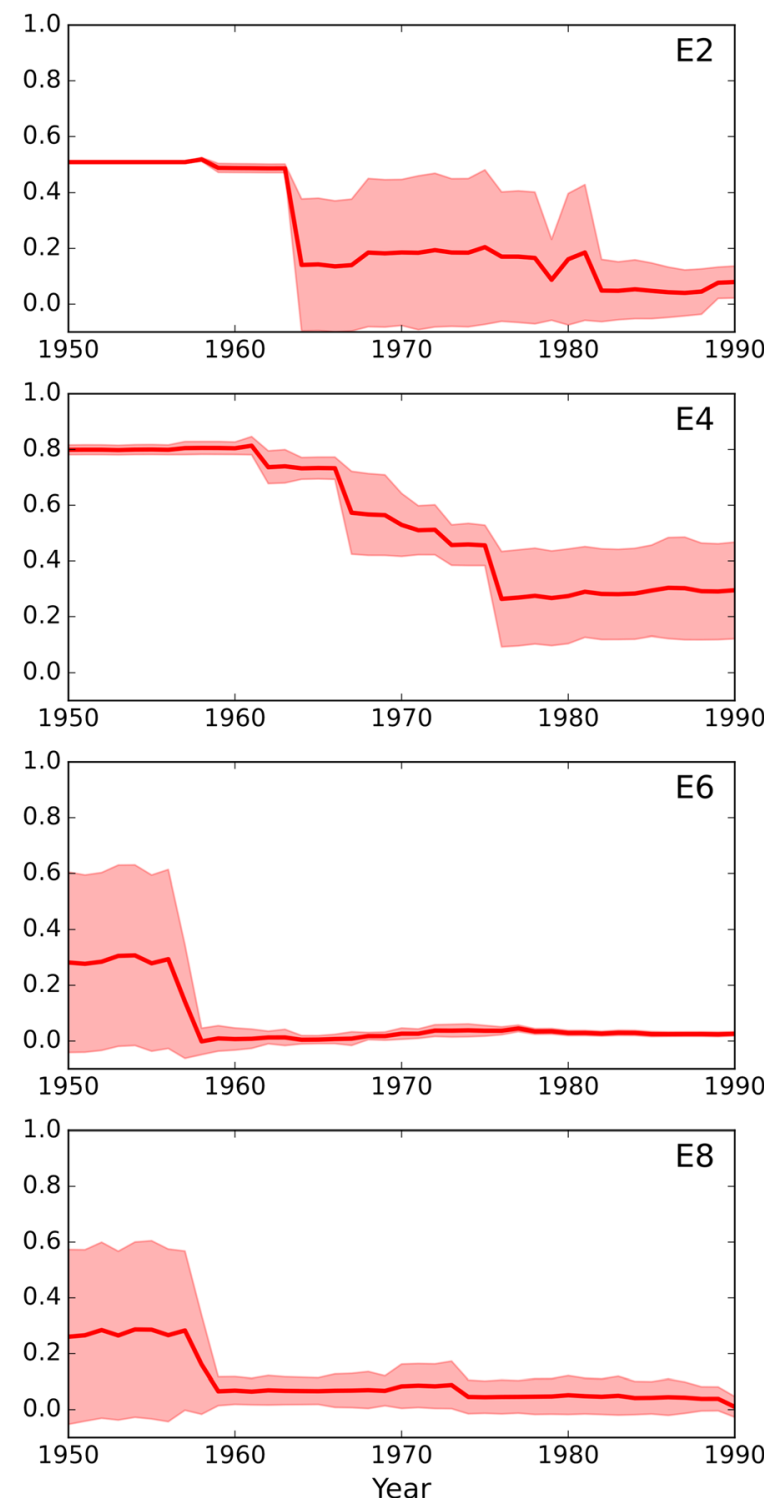

Fig. 10 The mean magnitude adjustment and the range of adjustments (or standard deviation) over time for eight fictitious earthquake epicentres shown in Fig. 3 (E1-E8) assuming seismic networks of variable up-time 
the seismometer selection process was repeated 1,000 times. Figure 10 shows the mean magnitude adjustment and the range of the possible adjustments (i.e., standard deviation about the mean) over time assuming seismic networks of variable up-time. Commonly, the magnitude adjustment factor will start out being a large value (i.e., greater than 0.5 magnitude units) during the early instrumental era and reduce over time as seismic networks densified. In some cases (E1-E5), the variability of the adjustment is low in the earlier years because there are often no alternative stations within the 1,500 km range. As seismic networks become denser, the range of potential adjustments for epicentres $E 1-E 5$ increases. The fictitious epicentres located in southeastern Australia (E6 and E8) have the smallest potential adjustments from the late 1950s (including the range of adjustments) because dense seismic networks in this region were established much earlier than in other, more remote areas of the continent.

This sensitivity analysis was intended to explore the potential uncertainty in the magnitude adjustment procedure introduced by assumptions in network configuration over time. Based on the fictitious earthquake locations shown in Fig. 3, the potential uncertainty in the magnitude adjustment factor for earthquakes in Australia varies both in time and in space, with the standard deviation about the mean adjustment being about 0.3 magnitude units, or larger, in some cases. Therefore, accounting for network up-time leads to yet further uncertainties that should be considered in any magnitude adjustment.

\section{Discussion}

An earthquake catalogue with consistently derived magnitudes through time is essential for seismic hazard assessments, particularly in SCRs that have limited information on active faults and where distributed seismicity sources often dominate the hazard profile. While moment magnitude has become the de facto magnitude type used in seismic hazard assessments given its relationship to the physical rupture process and superior performance over a broad range of magnitudes (Hanks and Kanamori 1979), $M_{\mathrm{W}}$ is not commonly calculated for small-to-moderate earthquakes by many regional and national observatories (e.g., Allen et al. 2018b; Grünthal and Wahlström 2012; Halchuk et al. 2015; Mueller 2019). In lieu of a consistently derived $M_{\mathrm{W}}$ catalogue, it is common to convert from other magnitude scales to $M_{\mathrm{W}}$ for seismic hazard assessments. A particular challenge for Australia is that the $M_{\mathrm{L}}$ relationships used by national, state, university and private seismic observatories have not been consistent over time. This has led to an earthquake catalogue that provides inconsistent magnitudes for an earthquake of given energy release, both spatially and temporally. This draws into question whether earthquake catalogues based on sparse network recordings or felt report data can be relied upon to determine accurate earthquake recurrence statistics. This issue is explored below. Furthermore, considerations for other data-poor regions are also considered, as well as opportunities for future improvement.

Are the adjustments worth it? As we have seen above, there are still significant uncertainties in local magnitude estimation for Australian earthquakes, even with modern instrumental networks where median uncertainties exceed 0.3 magnitude in all regions of the continent (Fig. 9). This raises broader questions around the pursuit to include historical earthquakes, particularly pre-instrumental, in the characterisation of earthquake rates where magnitude uncertainties are likely to exceed 0.5 magnitude units (e.g., McGuire 1993). Furthermore, any attempts to adjust catalogue magnitudes to compensate for the use of inappropriate magnitude formulae will lead to additional uncertainty. Sensitivity testing of these uncertainties suggest the uncertainty associated with the adjustment of early instrumental local magnitudes may exceed 0.3 magnitude units, particularly for early instrumental periods (Fig. 10). Combining these uncertainties (given by root sum of the squares) may thus lead to significant magnitude uncertainties for any given earthquake.

In "data-rich" active tectonic regions, studies have shown that the inclusion of poorer-quality magnitudes from the early instrumental era diminishes the reliability of earthquake recurrence estimates. For example, Habermann (1986) demonstrated that changes in seismic network configuration in California led to systematic changes in earthquake magnitude estimates over time. The Habermann (1986) study did not attribute these magnitude changes to limitations in the magnitude algorithms in use at the time. Nevertheless, not accounting for the observed biases due to changing network configurations will lead to biases in seismic rate estimates. In another study, Bent and Greene (2014) 
identify a small change in network magnitudes for eastern Canada due to changes in the network configuration over time. However, they concede this finding is not statistically significant, suggesting that the chosen magnitude algorithm used for local earthquakes (i.e., Nuttli 1973 ) is not markedly biased with distance.

Studies have shown that uncertainties in magnitude estimation can lead to either positive (e.g., Kijko et al. 2016; Leptokaropoulos et al. 2018; Tinti and Mulargia 1985) or negative (McGuire 1993; Veneziano and Van Dyke 1985) biases in earthquake rates. The direction of the bias depends on whether earthquake magnitudes are converted from another value (and how), or whether the uncertainty is simply a function of the measurement error of the magnitude type being considered (Musson 2012). However, these broad generalisations assume that uncertainties follow a homoscedastic distribution in space, time and magnitude, so the reality in the underestimation or overestimation in earthquake rates is likely to be more complex. Rhoades (1996) showed that increasing uncertainty in magnitude estimation was correlated to increasing magnitude in New Zealand. When mapped to earthquake rate calculations, the larger uncertainties for larger magnitudes lead to a flattening of the Gutenberg-Richter magnitude-frequency recurrence curve with lower $b$-values, and a consequent overestimation of larger events (Rhoades and Dowrick 2000). In the New Zealand case, the cause of magnitude variation was not explicitly discussed by Rhoades (1996); however, it is plausible that such uncertainties could be due to poorly calibrated magnitude correction factors that are ill-equipped to capture the attenuation properties of highly heterogeneous crust of New Zealand (e.g., Eberhart-Phillips et al. 2015; Rhoades et al. 2020). Any such variability from poorly calibrated attenuation models would be exacerbated for larger earthquakes that are recorded over a larger distance range, with seismic waves sampling increasingly complex crust of different attenuation characteristics. While the Australian continental crust is less heterogeneous than may be expected in plate boundary settings, similar far-field variability in ground-motion amplitudes and magnitudes may be observed, particularly given the sparse recording network. Uncertainty in the earthquake magnitude may be further exacerbated if a poorly calibrated magnitude algorithm is used.

In Australia, many of the pre-instrumental earthquakes are, by virtue of being widely felt by communities, those that have been assigned with larger magnitudes. Taking the findings of Rhoades (1996), we may assume that the consideration of such events in the estimation of Gutenberg-Richter statistics may lead to an overestimation of earthquake rates for larger events. This effect has been demonstrated in recent studies (e.g., Beauval et al. 2020; Rong et al. 2011) where the authors find that the historical rate of seismicity exceeds that of modern instrumental earthquake catalogues. While minor perturbations in earthquake occurrence commonly occur at local or regional scales, it should be expected that earthquake rates from modern data at continental scales, or in regions where the seismicity has been comparatively stationary in space and time (Allen et al. 2020; Leonard 2008), are more consistent with the true long-term rates of seismicity.

In regions that are comparatively "data poor", it is common for seismic hazard studies to take advantage of pre-instrumental earthquake records to extend the observation period. However, we must also consider the relative value, and trade-offs associated with these decisions. Preserving the pre-instrumental earthquake record is important and these events should be represented in earthquake catalogues to provide a benchmark for modern seismic hazard studies. However, do the large uncertainties on their magnitude estimations dilute the quality of earthquake rate calculations that may be achieved from the use of modern earthquake catalogues alone, even for data-poor regions like Australia? While this manuscript does not attempt to quantify this question, it raises important issues around the inclusion of such data and its benefits for long-terms seismic hazard analysis. Therefore, we must consider whether the magnitude adjustments proposed herein are worth implementing given the existing uncertainties of magnitude estimation for even relatively recent events. That is, would the recurrence statistics benefit from only using data from the modern instrumental era? Such an approach is unlikely to achieve consensus in Australia in the foreseeable future (e.g., Griffin et al. 2020). Therefore, the use of the methods proposed herein is justified given the likely overestimation of early instrumental earthquake magnitudes, particularly for moderatemagnitude events due to the use of inappropriate magnitude formulae for earthquakes recorded at regional distances. To that end, it is the author's opinion that the corrections undertaken herein yield more sensible magnitudes for many early instrumental earthquakes in the Australian catalogue. Furthermore, the rates of 
pre-1990 moderate-to-large earthquakes based on the adjusted magnitudes are more consistent with current earthquake rates (e.g., Fig. 4). Nevertheless, it is recommended that future research be undertaken to improve the characterisation of pre- and early instrumental earthquake magnitudes. This may require investigation into and digitisation of early paper archives to retrieve primary source data, and the review of earthquake source parameters based on macroseismic intensity data (e.g., Griffin et al. 2019; McCue 1980).

Considerations for other regions While the discussion herein has focussed on the Australian situation, there are potentially other regions in the world where similar problems in earthquake catalogues may exist. In the Western Canadian Sedimentary Basin (WCSB) region for example, two recent studies (Babaie Mahani and Kao 2019; Yenier 2017) develop updated local magnitude attenuation correction factors that suggest that the use of Richter (1935) - as used for Natural Resources Canada's earthquake catalogue for western Canadatends to overestimate magnitudes by up to 0.6 magnitude units for some earthquakes. Yenier (2017) finds that the standard Richter $M_{\mathrm{L}}$ fails to capture the complexity of the attenuation of observed ground motions in the WCSB, which are affected by critical Moho reflections (e.g., Burger et al. 1987), an effect that is also observed in the attenuation of Wood-Anderson displacement amplitudes in southeastern Australia (unpublished work).

Given seismic hazard assessments in lower seismicity regions are dependent on earthquake catalogues, accurate estimates of local magnitudes are critical for robust determination of Gutenberg-Richter magnitudefrequency statistics. Biases mapped into magnitude formulae can have a significant effect on these statistics as they are likely to bias the magnitudes of larger magnitude events disproportionately more given they are recorded over a longer distance range (e.g., see Fig. 1). The most recent generation of the Seismic Hazard Model of Canada (Adams et al. 2019; Kolaj et al. 2020) relies on the 2010 Seismic Hazard Earthquake Epicentre File (SHEEF 2010; Halchuk et al. 2015). This catalogue assumes that $M_{\mathrm{W}}=M_{\mathrm{L}}$ for onshore Western Canada (Ristau et al. 2005). If earthquakes occurring in the WCSB have been systematically overestimated owing to the use of the Richter (1935), developed for southern California, this may lead to the overestimation of rates for moderate to large-magnitude earthquakes, potentially leading to an overestimated estimate of seismic hazard for that region.

While the Canadian case represents one example, the use of inappropriate or poorly calibrated magnitude formulae may be a consideration for other regions of lower seismicity levels, particularly those that have been sparsely instrumented over time.

Future challenges and opportunities To address ongoing challenges for catalogue improvement, Geoscience Australia is digitising printed and hand-written observations preserved on earthquake data sheets. Once complete, this information will provide a valuable resource that will allow for further interrogation of pre-digital data and enable refinement of early instrumental catalogues.

With the passing of some three decades since the development of Australian-specific $M_{\mathrm{L}}$ formulae currently used in observational practice, there is now a relative abundance of high-quality digital waveform data recorded from Australian earthquakes. These data may be used to develop new, more accurate local magnitude formulae that consider more complex propagation wave paths, such as critical reflections from the Moho as observed in Fourier spectral analyses in eastern Australia (Allen et al. 2007). With the continued improvement and densification of seismic monitoring infrastructure within Australia, the uncertainty in magnitude estimation may be reduced if combined with improved local magnitude calculation techniques.

While this objective could be readily achieved with modern datasets, there is a risk that another change in magnitude estimation methods may introduce yet another step-change in Australian earthquake catalogues. Therefore, any change in magnitude formulation must be carefully documented and managed to ensure the continuity of catalogue magnitudes, and its potential flow-on effects to seismic hazard assessments.

Finally, legacy macroseismic intensity data (e.g., Everingham et al. 1982; McCue 1996; Rynn et al. 1987) may be reinterpreted to calculate $M_{\mathrm{W}}$-equivalent magnitudes (e.g., Griffin et al. 2019) using modern intensity attenuation methods that model the intensity attenuation characteristics of the Australian continental crust. These attenuation models would use data from modern earthquakes with calculated instrumental moment magnitudes, and may consider amplification effects owing to seismic site conditions (e.g., McPherson 
2017). The consistency of macroseismic intensity observations collected over time should be explored to ensure that the legacy data is consistent with the modern data used to calibrate an Australian-specific intensity attenuation model.

\section{Conclusion}

A pragmatic method has been developed that corrects magnitudes using the difference between the original (inappropriate) magnitude formula and the Australianspecific corrections at a distance determined by the nearest recording station likely to have recorded the earthquake. The objective of revising magnitudes is not to produce a PSHA-ready catalogue in terms of moment magnitude, but to deliver an interim earthquake catalogue that provides consistently derived local magnitudes for the time period of interest.

Nationally, the use of this magnitude adjustment method has led to a general reduction in the rates of earthquakes, particularly for moderate magnitudes, reducing the number of $M_{\mathrm{L}} \geq 4.5$ earthquakes by about $25 \%$ since 1900 , with a reduction of approximately $32 \%$ of $M_{\mathrm{L}} \geq 5.0$ earthquakes over the same period. Without undertaking these corrections, the catalogue would comprise earthquake magnitudes determined from disparate local magnitude equations for the same region, adding significant uncertainty to earthquake recurrence calculations. This is particularly true for the recurrence of moderate-to-large earthquakes in the Australian earthquake catalogue, which have likely been overestimated due to the past use of poorly calibrated attenuation formulae, which can yield highly variable station magnitudes over a large range of source-receiver distances. Therefore, these magnitude adjustments allow seismic hazard practitioners to develop improved hazard assessments based on catalogues that are less likely to overestimate rates of moderate-to-large earthquakes in Australia.

Acknowledgements The development of any earthquake catalogue that is suitable for use in seismic hazard assessments is a complex undertaking, and has involved many of our colleagues, past and present, at Geoscience Australia (and its predecessors), as well as other catalogue authorities. The author is indebted to the compilers of these catalogues that underpin the NSHA18-Cat. Russell Cuthbertson is thanked for providing a list of Australian seismic stations with their period of activity and his review comments. Phil Cummins, Hadi Ghasemi and Tanja Pejić are thanked for their internal reviews of this document. The author also thanks two anonymous reviewers for their thoughtful comments. Finally, we also thank colleagues from the Australian and international seismological communities for challenging decisions made by the authors in the development of the NSHA18-Cat. These robust discussions have led to a higher level of scrutiny of the NSHA18-Cat and have strengthened the scientific integrity in the development of the catalogue.

Code availability Codes used to undertake magnitude adjustments for the NSHA18 earthquake catalogue are available here: https://github.com/GeoscienceAustralia/NSHA2018 /blob/master/licence/README.MD

Funding This research was supported by the author's employer, the Commonwealth of Australia (Geoscience Australia).

Data availability Earthquake catalogue data used in these analyses are available through the data package available with the NSHA18 earthquake catalogue (Allen et al. 2018b). A list of stations and on/off dates are found at the following link: https://github.com/GeoscienceAustralia/ga-earthquakehazard/tree/master/ml_adjustments

\section{Declarations}

Competing interests The authors declare no competing interests.

Open Access This article is licensed under a Creative Commons Attribution 4.0 International License, which permits use, sharing, adaptation, distribution and reproduction in any medium or format, as long as you give appropriate credit to the original author(s) and the source, provide a link to the Creative Commons licence, and indicate if changes were made. The images or other third party material in this article are included in the article's Creative Commons licence, unless indicated otherwise in a credit line to the material. If material is not included in the article's Creative Commons licence and your intended use is not permitted by statutory regulation or exceeds the permitted use, you will need to obtain permission directly from the copyright holder. To view a copy of this licence, visit http://creativecommons.org/licenses/by/4.0/.

\section{References}

Adams J, Allen T, Halchuk S, Kolaj M (2019) Canada's $6^{\text {th }}$ Generation Seismic Hazard Model, as prepared for the 2020 National Building Code of Canada. 12 ${ }^{\text {th }}$ Canadian Conference on Earthquake Engineering, Québec City, Québec, Paper 192-Mkvp-139

Allen TI (2010) The influence of attenuation in earthquake ground-motion and magnitude estimation: implications for 
Australian earthquake hazard. Australian Earthquake Engineering Society Conference, Perth, Western Australia

Allen TI (2012) Stochastic ground-motion prediction equations for southeastern Australian earthquakes using updated source and attenuation parameters. Geoscience Australia Record 69:55

Allen TI, Cummins PR, Dhu T, Schneider JF (2007) Attenuation of ground-motion spectral amplitudes in southeastern Australia. Bull Seismol Soc Am 97(4):1279-1292. https://doi.org/10.1785/0120060172

Allen T, Griffin J, Leonard M, Clark D, Ghasemi H (2018a) National Seismic Hazard Assessment for Australia: model overview. Geoscience Australia Record 201827126 https://doi.org/10.11636/Record.2018.027

Allen TI, Leonard M, Ghasemi H, Gibson G (2018b) National Seismic Hazard Assessment for Australia: earthquake epicentre catalogue. Geoscience Australia Record 30:51. https://doi.org/10.11636/Record.2018.030

Allen TI, Griffin JD, Leonard M, Clark DJ, Ghasemi H (2020) The 2018 National Seismic Hazard Assessment of Australia: quantifying hazard changes and model uncertainties. Earthquake Spectra 36(S1):5-43. https://doi.org/10.1177 $/ 8755293019900777$

Amato A, Mele FM (2008) Performance of the INGV National Seismic Network from 1997 to 2007. Ann Geophys 51(2/3): 417-431. https://doi.org/10.4401/ag-4454

Anderson JA, Wood HO (1925) Description and theory of the torsion seismometer. Bull Seismol Soc Am 15(1):1-72

Babaie Mahani A, Kao H (2019) Accurate determination of local magnitude for earthquakes in the Western Canada Sedimentary Basin. Seismol Res Lett 90:203-211. https://doi.org/10.1785/0220180264

Bakun WH, Joyner WB (1984) The $M_{L}$ scale in central California. Bull Seismol Soc Am 74(5):1827-1843

Beauval C, Bard P-Y, Danciu L (2020) The influence of sourceand ground-motion model choices on probabilistic seismic hazard levels at 6 sites in France. Bull Earthq Eng 18:45514580. https://doi.org/10.1007/s10518-020-00879-z

Bent A, Greene H (2014) Toward an improved understanding of the $M_{\mathrm{N}}-M_{\mathrm{W}}$ time dependence in eastern Canada. Bull Seismol Soc Am 104(4):2125-2132. https://doi.org/10.1785 /0120140031

Bindi D, Zaccarelli R, Strollo A, Di Giacomo D (2019) Harmonized local magnitude attenuation function for Europe using the European Integrated Data Archive (EIDA). Geophys J Int 218(1):519-533. https://doi. org/10.1093/gii/ggz178

Bommer JJ, Coppersmith KJ, Coppersmith RT, Hanson KL, Mangongolo A, Neveling J, Rathje EM, Rodriguez-Marek A, Scherbaum F, Shelembe R, Stafford PJ, Strasser FO (2015) A SSHAC level 3 probabilistic seismic hazard analysis for a new-build nuclear site in South Africa. Earthquake Spectra 31(2):661-698. https://doi.org/10.1193/060913 EQS145M

Boore DM (2002) SMSIM — Fortran programs for simulating ground motions from earthquakes: version 2.0 - a revision of OFR 96-80-A. U.S. Geological Survey Open-File Report 509:56

Brown A, Gibson G, Sinadinovski C, McCue K (2001) Measurements of PGA and attenuation in southeastern Australia. New Zealand Society of Earthquake Engineering
2001 Conference, Wairakei, New Zealand, Paper No. 1.02.01

Burbidge DR (2012) The 2012 Australian Earthquake Hazard Map. Geoscience Australia Record 71:116

Burger RW, Somerville PG, Barker JS, Herrmann RB, Helmberger DV (1987) The effect of crustal structure on strong ground motion attenuation relations in eastern North America. Bull Seismol Soc Am 77(2):420-439

Burkhard M, Grünthal G (2009) Seismic source zone characterization for the seismic hazard assessment project PEGASOS by the Expert Group 2 (EG1b). Swiss J Geosci 102:149-188. https://doi.org/10.1007/s00015-009-1307-3

Castellaro S, Mulargia F, Kagan YY (2006) Regression problems for magnitudes. Geophys J Int 165:913-930. https://doi. org/10.1111/j.1365-246X.2006.02955.x

Cuthbertson RJ (2016) Automatic determination of seismicity rates in Australia. Australian Earthquake Engineering Society 2016 Conference, Melbourne, Victoria

Danciu L, Șeșetyan K, Demircioglu M, Gülen L, Zare M, Basili R, Elias A, Adamia S, Tsereteli N, Yalçın H, Utkucu M, Khan MA, Sayab M, Hessami K, Rovida AN, Stucchi M, Burg J-P, Karakhanian A, Babayan H, Avanesyan M, Mammadli T, Al-Qaryouti M, Kalafat D, Varazanashvili O, Erdik M, Giardini D (2018) The 2014 Earthquake Model of the Middle East: seismogenic sources. Bull Earthq Eng 16(8): 3465-3496. https://doi.org/10.1007/s10518-017-0096-8

Denham D (1982) Proceedings of the workshop on Australian earthquake magnitude scales. Bureau of Mineral Resources Record 1982/29:pp 36

Denham D, Gibson G, Smith RS, Underwood R (1985) Source mechanisms and strong ground motion from the 1982 Wonnangatta and the 1966 Mount Hotham earthquakes. Aust J Earth Sci 32(1):37-46. https://doi.org/10.1080 /08120098508729310

Drake L (1974) The seismicity of New South Wales. Proc R Soc NSW 107:35-40

Eberhart-Phillips D, Reyners M, Bannister S (2015) A 3D $Q_{P}$ attenuation model for all of New Zealand. Seismol Res Lett 86(6):1655-1663. https://doi.org/10.1785/0220150124

Eiby GA, Muir MG (1961) Tables to facilitate the study of near earthquakes. New Zealand Department of Scientific and Industrial Research, Seismological Observatory Bulletin S-109

Everingham IB, McEwin AJ, Denham D (1982) Atlas of isoseismal maps of Australian earthquakes. Bureau of Mineral Resources, Geology and Geophysics Bulletin 214

Gaull BA, Gregson PJ (1991) A new local magnitude scale for Western Australian earthquakes. Aust J Earth Sci 38(3):251260. https://doi.org/10.1080/08120099108727970

Gerstenberger MC, Marzocchi W, Allen T, Pagani M, Adams J, Danciu L, Field E, Fujiwara H, Luco N, Ma K-F, Meletti C, Petersen M (2020) Probabilistic seismic hazard analysis at regional and national scale: state of the art and future challenges. Rev Geophys 58(2):e2019RG000653. https://doi. org/10.1029/2019RG000653

Ghasemi H, Allen T (2017) Testing the sensitivity of new Australian empirical magnitude conversion equations on seismic hazard analyses. Australian Earthquake Engineering Society Conference, Canberra, ACT 
Gibson G, Dimas V-A (2009) Earthquake hazard at Newcastle. Australian Earthquake Engineering Society Conference, Newcastle, New South Wales

Gibson G, Sandiford M (2013) Seismicity \& induced earthquakes: report commissioned for the Independent Review of coal seam gas activities in NSW by the NSW Chief Scientist \& Engineer. Melbourne Energy Institute, University of Melbourne:pp 33

Greenhalgh SA, Singh R (1986) A revised magnitude scale for South Australian earthquakes. Bull Seismol Soc Am 76(3): 757-769

Griffin J, Nguyen N, Cummins P, Cipta A (2019) Historical earthquakes of the Eastern Sunda Arc: source mechanisms and intensity-based testing of Indonesia's National Seismic Hazard Assessment. Bull Seismol Soc Am 109(1):43-65. https://doi.org/10.1785/0120180085

Griffin JD, Allen TI, Gerstenberger MC (2020) Seismic hazard assessment in Australia: can structured expert elicitation achieve consensus in the "land of the fair go"? Seismol Res Lett 91(2A):859-873. https://doi.org/10.1785/0220190186

Grünthal G, Wahlström R (2003) An $\mathrm{M}_{\mathrm{W}}$ based earthquake catalogue for central, northern and northwestern Europe using a hierarchy of magnitude conversions. J Seismol 7:507-531

Grünthal G, Wahlström R (2012) The European-Mediterranean Earthquake Catalogue (EMEC) for the last millennium. $\mathrm{J}$ Seismol 16:535-570. https://doi.org/10.1007/s10950-0129302-y

Grünthal G, Stromeyer D, Bosse C, Cotton F, Bindi D (2018) The probabilistic seismic hazard assessment of Germanyversion 2016, considering the range of epistemic uncertainties and aleatory variability. Bull Earthq Eng 16(10): 4339-4395. https://doi.org/10.1007/s10518-018-0315-y

Gutenberg B, Richter CF (1944) Frequency of earthquakes in California. Bull Seismol Soc Am 34(4):185-188

Habermann RE (1986) A test of two techniques for recognizing systematic errors in magnitude estimates using data from Parkfield, California. Bull Seismol Soc Am 76(6):16601667

Halchuk S, Allen TI, Rogers GC, Adams J (2015) Seismic Hazard Earthquake Epicentre File (SHEEF2010) used in the Fifth Generation Seismic Hazard Maps of Canada. Geological Survey of Canada Open File 7724:16. https://doi. org/10.4095/296908

Hanks TC, Kanamori H (1979) A moment magnitude scale. J Geophys Res 84(B5):2348-2350. https://doi.org/10.1029 /JB084iB05p02348

Hutton LK, Boore DM (1987) The $M_{L}$ scale in southern California. Bull Seismol Soc Am 77(6):2074-2094

Hutton K, Woessner J, Hauksson E (2010) Earthquake monitoring in southern California for seventy-seven years (1932-2008). Bull Seismol Soc Am 100(2):423-446. https://doi. org/10.1785/0120090130

Kijko A, Smit A, Sellevoll MA (2016) Estimation of earthquake hazard parameters from incomplete data files. Part III. Incorporation of uncertainty of earthquake-occurrence model. Bull Seismol Soc Am 106(3):1210-1222. https://doi. org/10.1785/0120150252

Kolaj M, Adams J, Halchuk S (2020) The $6^{\text {th }}$ Generation seismic hazard model of Canada. $17^{\text {th }}$ World Conference on Earthquake Engineering, Sendai, Japan, Paper 1c-0028
Leonard M (2008) One hundred years of earthquake recording in Australia. Bull Seismol Soc Am 98(3):1458-1470. https://doi.org/10.1785/0120050193

Leonard M, Burbidge DR, Allen TI, Robinson DJ, McPherson A, Clark D, Collins CDN (2014a) The challenges of probabilistic seismic-hazard assessment in stable continental interiors: an Australian example. Bull Seismol Soc Am 104(6):3008 3028. https://doi.org/10.1785/0120130248

Leonard M, Hoult R, Somerville P, Gibson G, Sandiford D, Goldsworthy H, Lumantarna E, Spiliopoulos S (2014b) Deaggregating the differences between seismic hazard assessments at a single site. Australian Earthquake Engineering Society Conference, Lorne, Victoria

Leptokaropoulos KM, Adamaki AK, Roberts RG, Gkarlaouni CG, Paradisopoulou PM (2018) Impact of magnitude uncertainties on seismic catalogue properties. Geophys J Int 213(2):940-951. https://doi.org/10.1093/gji/ggy023

McCue K (1980) Magnitude of some early earthquakes in southeastern Australia. Search 11(3):78-80

McCue K (1996) Atlas of isoseismal maps of Australian earthquakes, part 3. Australian Geological Survey Organisation AGSO Record 1995/44

McCue K, Wesson V, Gibson G (1990) The Newcastle, New South Wales, earthquake of 28 December 1989. BMR J Aust Geol Geophys 11(4):559-567

McGregor PM, Ripper ID (1976) Notes of earthquake magnitude scales Bureau of Mineral Resources Record 56

McGuire RK (1993) Computations of seismic hazard. Ann Geophys 36(3-4):181-200. https://doi.org/10.4401/ag-4263

McPherson AA (2017) A revised seismic site conditions map for Australia. Geoscience Australia Record 12. https://doi. org/10.11636/Record.2017.012

Michael-Leiba M, Malafant K (1992) A new local magnitude scale for southeastern Australia. BMR J Aust Geol Geophys 13(3): 201-205

Mueller CS (2019) Earthquake catalogs for the USGS National Seismic Hazard Maps. Seismol Res Lett 90(1):251-261. https://doi.org/10.1785/0220170108

Musson RMW (2012) The effect of magnitude uncertainty on earthquake activity rates. Bull Seismol Soc Am 102(6): 2771-2775. https://doi.org/10.1785/0120110224

Nuttli OW (1973) Seismic wave attenuation and magnitude relations for eastern North America. J Geophys Res 78(5):876885. https://doi.org/10.1029/JB078i005p00876

Onur T, Gok R, Godoladze T, Gunia I, Boichenko G, Buzaladze A, Tumanova N, Dzmanashvili M, Sukhishvili L, Javakashvili Z, Cowgill E, Bondár I, Yetirmishli G (2020) Probabilistic seismic hazard assessment using legacy data in Georgia. Seismol Res Lett 91(3):1500-1517. https://doi. org/10.1785/0220190331

Peck W (2016) An earthquake alarm and situation awareness tool developed for areas of low to moderate seismic hazard: recent developments and past results. Australian National Committee on Large Dams / New Zealand Society of Large Dams Conference, Adelaide, South Australia

Peterson J, Hutt CR (1981) Preliminary design study for a National Digital Seismograph Network. U.S. Geological Survey 81(1046):55. https://doi.org/10.3133/ofr811046

Rhoades DA (1996) Estimation of the Gutenberg-Richter relation allowing for individual earthquake magnitude uncertainties. 
Tectonophys 258(1-4):71-83. https://doi.org/10.1016/00401951(95)00182-4

Rhoades DA, Dowrick DJ (2000) Effects of magnitude uncertainties on seismic hazard estimates. $12^{\text {th }}$ World Conference on Earthquake Engineering, Auckland, New Zealand, Paper 1179

Rhoades DA, Christophersen A, Bourguignon S, Ristau J, Salichon J (2020) A depth-dependent local magnitude scale for New Zealand earthquakes consistent with moment magnitude. Bull Seismol Soc Am. https://doi.org/10.1785 /0120200252

Richter CF (1935) An instrumental earthquake magnitude scale. Bull Seismol Soc Am 25(1):1-32

Richter CF (1958) Elementary seismology. W. H. Freeman and Co., San Francisco, California

Ristau J, Rogers GC, Cassidy JF (2005) Moment magnitude-local magnitude calibration for earthquakes in western Canada. Bull Seismol Soc Am 95(5):1994-2000. https://doi. org/10.1785/0120050028

Ristau J, Harte D, Salichon J (2016) A revised local magnitude $\left(M_{L}\right)$ scale for New Zealand earthquakes. Bull Seismol Soc Am 106(2):398-407. https://doi.org/10.1785/0120150293

Rong Y, Mahdyiar M, Shen-Tu B, Shabestari K (2011) Magnitude problems in historical earthquake catalogues and their impact on seismic hazard assessment. Geophys J Int 187:16871698. https://doi.org/10.1111/j.1365-246X.2011.05226.x

Rynn JMW, Denham D, Greenhalgh S, Jones T, Gregson PJ, McCue KF, Smith RS (1987) Atlas of isoseismal maps of Australian earthquakes, part 2. Bureau of Mineral Resources Geology and Geophysics BMR Bulletin 222. https://doi. org $/ 10.26186 / 5$ c63cf93385f2

Saunders I, Ottemöller L, Brandt MBC, Fourie CJS (2013) Calibration of an $M_{L}$ scale for South Africa using tectonic earthquake data recorded by the South African National Seismograph Network: 2006 to 2009. J Seismol 17(2):437451. https://doi.org/10.1007/s10950-012-9329-0

Storchak DA, Harris J, Brown L, Lieser K, Shumba B, Verney R, Di Giacomo D, Korger EIM (2017) Rebuild of the Bulletin of the International Seismological Centre (ISC), part 1: 1964 1979. Geosci Lett 4:32. https://doi.org/10.1186/s40562-0170098-Z

Storchak DA, Harris J, Brown L, Lieser K, Shumba B, Di Giacomo D (2020) Rebuild of the Bulletin of the International Seismological Centre (ISC) - part 2: 19802010. Geosci Lett 7:18. https://doi.org/10.1186/s40562020-00164-6

Stucchi M, Rovida A, Gomez Capera AA, Alexandre P, Camelbeeck T, Demircioglu MB, Gasperini P, Kouskouna V, Musson RMW, Radulian M, Sesetyan K, Vilanova S, Baumont D, Bungum H, Fäh D, Lenhardt W, Makropoulos K, Martinez Solares JM, Scotti O, Živčić M, Albini P, Batllo
J, Papaioannou C, Tatevossian R, Locati M, Meletti C, Viganò D, Giardini D (2013) The SHARE European Earthquake Catalogue (SHEEC) 1000-1899. J Seismol 17(2):523-544. https://doi.org/10.1007/s10950-012-9335-2

Tinti S, Mulargia F (1985) Effects of magnitude uncertainties on estimating the parameters in the Gutenberg-Richter frequency-magnitude law. Bull Seismol Soc Am 75(6):1681-1697

Traversa P, Baumont D, Manchuel K, Nayman E, Durouchoux C (2018) Exploration tree approach to estimate historical earthquakes Mw and depth, test cases from the French past seismicity. Bull Earthq Eng 16:2169-2193. https://doi. org/10.1007/s10518-017-0178-7

Uhrhammer RA, Hellweg M, Hutton K, Lombard P, Walters AW, Hauksson E, Oppenheimer D (2011) California Integrated Seismic Network (CISN) local magnitude determination in California and vicinity. Bull Seismol Soc Am 101(6):26852693. https://doi.org/10.1785/0120100106

Veneziano D, Van Dyke J (1985) Seismic parameter estimation methods. In: EPRI/SOG (ed) Seismic Hazard Methodology for Nuclear Facilities in the Eastern United States (Draft 851), 2. p Appendix A

Weatherill GA, Pagani M, Garcia J (2016) Exploring earthquake databases for the creation of magnitude-homogeneous catalogues: tools for application on a regional and global scale. Geophys J Int 206:1652-1676. https://doi.org/10.1093 /gji/ggw232

Weichert DH (1980) Estimation of the earthquake recurrence parameters for unequal observation periods for different magnitudes. Bull Seismol Soc Am 80(70):1337-1346

White RE (1968) A local magnitude scale for South Australian earthquakes. Bull Seismol Soc Am 58(3):1041-1057

Wilkie JR (1996) Earthquake source parameters, Victoria, Australia. Doctor of Philosophy, La Trobe University, Melbourne

Wilkie J, Gibson G, Wesson V (1994) Richter magnitudes and site corrections using vertical component seismograms. Aust J Earth Sci 41(3):221-228. https://doi.org/10.1080 /08120099408728131

Yenier E (2017) A local magnitude relation for earthquakes in the Western Canada sedimentary basin. Bull Seismol Soc Am 107(3):1421-1431. https://doi.org/10.1785/0120160275

Youngs RR (2012) Earthquake catalogue. In: Technical Report: Central and Eastern United States Seismic Source Characterization for Nuclear Facilities. EPRI, Palo Alto, CA, U.S. DOE, and U.S. NRC, Chapter 3

Publisher's note Springer Nature remains neutral with regard to jurisdictional claims in published maps and institutional affiliations. 